\title{
Fungal extracellular vesicles are involved in intraspecies intracellular communication
}

Authors. Tamires A. Bitencourt ${ }^{1}$, Otavio Hatanaka ${ }^{1}$, Andre M. Pessoni ${ }^{1}$, Mateus S. Freitas ${ }^{1}$, Gabriel Trentin ${ }^{1}$, Patrick Santos ${ }^{1}$, Antonio Rossi ${ }^{2}$, Nilce M. Martinez-Rossi ${ }^{2}$, Lysangela L. Alves ${ }^{3}$, Arturo Casadevall ${ }^{4}$, Marcio L. Rodrigues ${ }^{3,5}$, Fausto Almeida ${ }^{1 *}$.

\author{
Affiliation. \\ ${ }^{1}$ Department of Biochemistry and Immunology, Ribeirao Preto Medical School, \\ University of São Paulo, Ribeirao Preto, SP, Brazil \\ ${ }^{2}$ Department of Genetics, Ribeirão Preto Medical School, University of São Paulo, \\ Ribeirão Preto, São Paulo, Brazil \\ ${ }^{3}$ Gene Expression Regulation Laboratory, Carlos Chagas Institute, Fiocruz, Curitiba, \\ PR, Brazil \\ ${ }^{4}$ Department of Molecular Microbiology and Immunology, Johns Hopkins Bloomberg \\ School of Public Health, Baltimore, MD 21205, USA. \\ ${ }^{5}$ Instituto de Microbiologia Paulo de Góes, Universidade Federal do Rio de Janeiro, Rio \\ de Janeiro, Brazil \\ * Corresponding author
E-mail:fbralmeida@usp.br (FA)
}

Short-title- Extracellular Vesicles as communication mediators in fungi

Abstract

fungal diseases creates the urgent need to broaden the knowledge base regarding their pathophysiology. In this sense, the role of extracellular vesicles (EVs) has been described to convey biological information and participate in the fungal-host interaction process. EVs play many roles, including cellular physiology, responding to environmental cues, mediating a complex circuit of cellular communication in bidirectional crosstalk with other organisms, and the communication between fungal cells has been speculated. This study demonstrated the intra species uptake of EVs in 
Extracellular Vesicles as communication mediators in fungi

39 fungi, including Candida albicans, Aspergillus fumigatus, and Paracoccidioides

40 brasiliensis, and the effects triggered by EVs in fungal cells. In C. albicans, we

41 evaluated the involvement of EVs in yeast to hyphae transition, whilst in P. brasiliensis and A. fumigatus the function of EVs as stress transducers was investigated. Both $P$.

43 brasiliensis and A. fumigatus were exposed to an inhibitor of glycosylation or UV light,

44 respectively. The results demonstrated the role of EVs in regulating the expression of target genes and phenotype features. The EVs treatment induced cellular proliferation and boosted the transition yeast to hyphal transition in C. albicans, while they enhanced stress signals in A. fumigatus and P. brasiliensis, establishing a role for EVs in fungal intra species communication. Thus, fungal EVs regulate the virulence and adaptive traits in fungal interaction systems as potent message effectors, and understanding their

50 effects and mechanism(s) of action could be exploited in antifungal therapies.

Keywords: Fungal infections; cellular communication; extracellular vesicles; virulence; 52 fungal biology.

\section{Author Summary}

Extracellular vesicles (EVs) play an important role in export systems. They act as vehicles for the transference of complex cargoes with broad biological functions, such as proteins, carbohydrates, pigments, nucleic acids, and lipids. EVs can contribute to fungal infection outcomes. The EV content exerts immunomodulatory functions during fungus-host interactions. Furthermore, the participation of EVs in

60 communication between fungal cells has been speculated. This study investigated the 61 capacity of EVs to mediate intra-species in three genera of human pathogenic fungi and 62 established a regulatory function of EVs. We also assessed the features of this 63 regulation by analyzing the cellular morphological aspects of fungi after stimulation 
Extracellular Vesicles as communication mediators in fungi

64 with EVs. Our data suggest fungal EVs can function as potent signal mediators that

65 mediate virulence and adaptive responses.

66

67

\section{Introduction}

Fungal infections are responsible for over 1.6 million deaths per year. It is estimated that more than a billion cases of severe fungal diseases affect the world population. Despite these numbers it is likely that they represent an underestimate of the fungal diseases that ail humans $[1,2]$. The diseases caused by Aspergillus spp., Candida spp., and the endemic agent of mycoses such as Paracoccidioides species are among the deadliest mycoses $[1,2]$.

In recent years, extracellular vesicles (EVs) have been studied in cell-walled microorganisms. In fungi, they were first described in 2007 in Cryptococcus neoformans [3]. So far, EVs have been characterized in approximately 20 fungal species, including yeasts forms of $H$. capsulatum, Sporothrix schenckii, $C$. parapsilosis, Saccharomyces cerevisiae, Malassezia sympodialis, P. brasiliensis, $C$.

albicans, Pichia fermentans, C. gattii, S. brasiliensis, P. lutzii, and Exophiala dermatitidis [4-13] and filamentous fungi such as Alternaria infectoria, Trichophyton interdigitale, Rhizopus delemar, Fusarium oxysporum f. sp. Vasinfectum, Trichoderma reesei, Aspergillus fumigatus, and Aspergillus flavus [14-20].

EVs function as vehicles carrying complex cargoes with diverse biological functions, including proteins, carbohydrates, pigments, nucleic acids, and lipids. EVs can contribute to fungal infection outcomes [21]. EVs likely have roles in bi-directional communication, raising the possibility of communication between fungal cells [22]. Previous reports have demonstrated the participation of fungal EVs in biofilm formation [10], stimulation of cytokine production $[6,9,11,15,20,23]$, and favoring pathogen infection [4, 24]. Bidirectional communication mediated by fungal EVs has been 
Extracellular Vesicles as communication mediators in fungi

90 demonstrated in the interaction of fungal cells with plants $[25,26]$ and in

91 communication with mammalian cells [27, 28]. However, Intra fungal species

92 communication mediated by EVs has not been reported so far.

93 The possibility of EV-mediated virulence transfer and/or antifungal resistance

94 between strains have gathered attention. In the Cryptoccocus model, previous studies

95 demonstrated that the Vancouver Island outbreak strain of $C$. deuterogatti, namely

96 R265, can transfer its ability to proliferate within the host macrophages to an avirulent

97 strain, which was attributed as an EV-regulated process [11, 29]. Another report showed

98 that the supernatant from a highly virulent strain of $C$. neoformans culture stimulated

99 the pathogenic potential of a less virulent isolate, an effect also attributed to EVs [30].

100 Recently, a study advocated the role of EVs from $C$. albicans as messaging

101 compartments involved in growth, morphogenesis, and biofilm production [31]. These

102 studies postulated a role for fungal EVs in intra-species communication; however, at the

103 molecular level, many aspects related to the mechanisms switched on by EVs remain to

104 be investigated. Herein, we sought to analyze the fungal cellular communication

105 mediated by EVs using the fungal pathogens $P$. brasiliensis, A. fumigatus, and $C$.

106 albicans using multiple approaches. Our data demonstrate that fungal EVs mediate

107 cellular communication by regulating the expression of target genes and by controlling

108 cellular proliferation.

109

110 Results

111

112 Intercellular transfer of fungal EVs

114 Because EVs can transport multiple molecules that play essential roles in fungal 115 biology [22, 28, 32], we examined whether fungal EVs would be transferred 
Extracellular Vesicles as communication mediators in fungi

116 intercellularly from cells of the same species. Using $\left[1^{-14} \mathrm{C}\right]$ palmitic acid metabolic

117 labeling, radiolabeled fungal EVs were produced as previously described [33, 34].

118 Radioactive assays confirmed that fungal EVs produced by P. brasiliensis (Fig 1A), A.

119 fumigatus (Fig 1B), and C. albicans (Fig 1C) could be transferred from cell to cell

120 within the same species. We tracked the radioactivity added to the fungal cell cultures

121 during the time course after $0 \mathrm{~h}$ (control), $1 \mathrm{~h}, 6 \mathrm{~h}, 12 \mathrm{~h}$, and $24 \mathrm{~h}$ from the addition of

122 radiolabeled EVs to the cultures (Fig 1). The fungal cells were pelleted, washed with

123 PBS, and pulse-chase measurements were performed. We verified that purified

124 radiolabeled EVs were taken up by fungal cells as the radioactive signal increased over

125 time.

126

127 P. brasiliensis EVs as cellular communicator during Endoplasmic Reticulum (ER)

128 stress

We previously demonstrated that the genes PbHACA and PbIRE1 showed

131 increased expression during tunicamycin (TM) treatment [35], suggesting that they are

132 involved in the ER stress response of $P$. brasiliensis. Thus, we purified EVs from $P$.

133 brasiliensis treated with TM (TM EVs) and added these EVs to P. brasiliensis yeast

134 cells that did not receive TM treatment (Fig 2A). We observed that TM EVs increased

135 PbHACA and PbIRE1 expression significantly (red bars, Figs 2B and 2C, respectively).

136 On the other hand, fungal EVs obtained from P. brasiliensis yeast cells that were not

137 treated with TM (Pb EVs) added to P. brasiliensis yeast cells without TM treatment did

138 not alter PbIRE1 and PbHACA expression (blue bars, Figs 2B and 2C, respectively).

139 PBS was used as a negative control (white bar), while TM was the experimental group

140 (black bars). These results strongly suggested that $P$. brasiliensis EVs could participate 
Extracellular Vesicles as communication mediators in fungi

141 in intercellular communication during ER stress, possibly promoting fungal adaptive

142 responses.

\section{EVs from $A$. fumigatus act as stress message effectors}

144 To verify whether the observations made with $P$. brasiliensis applied to other 145 fungi, we isolated EVs from ultraviolet (UV) irradiated cultures and from non-irradiated

146 A. fumigatus cells (control). The EVs obtained from UV-treated cells were named UV

$147 \mathrm{EV}$, whereas the EVs obtained from regular cultures were named Control EV. Our data

148 showed an overall population size in the range of 100 to $200 \mathrm{~nm}$ and a minor population

149 of EVs with sizes varying from 320 to $394 \mathrm{~nm}$ in regular cultures or a range of 240 to

$150614 \mathrm{~nm}$ in cultures that underwent UV irradiation (S1 Fig).

151 EVs obtained from both A. fumigatus cultures after UV irradiation (UV EV) or

152 without UV irradiation (Control EV) (Fig 3A) caused a prominent decrease in colony

153 formation in A. fumigatus (Fig 3B). Approximately 40 percent of colony reduction was

154 achieved after EVs uptake (Fig 3B). Thereafter, the gene expression analysis reinforced

155 a possible role of these EVs as stress message effectors, showing the upregulation of the

$156 m p k C$ gene in both EVs uptake conditions. The $m p k C$ gene plays a role in adaptive

157 responses to different stress agents such as osmotic stress, oxidative stress, heat shock,

158 cell wall damage and also acts in cellular division regulation, as demonstrated in $A$.

159 fumigatus $[36,37]$. The cultures that received UV EV showed higher induction of the

$160 m p k C$ gene (Fig 3C). In addition, UV EV also caused a significant increase in the $a k u A$

161 transcript levels (Fig 3D), supporting a role of EVs in cellular communication events. In

162 addition, the presence of EVs caused a subtle downregulation of the nimA gene, which

163 may reflect another level of cell cycle regulation (Fig 3E).

164

165 EVs induce hyphae formation and regulate the cell cycle in $C$. albicans 
Extracellular Vesicles as communication mediators in fungi

hyphae culture in the $C$. albicans model would mediate communication signals that on cultures in YPD at $\mathrm{pH} 6.3$ at $30{ }^{\circ} \mathrm{C}$ were named as Control EV, whereas EVs obtained from C. albicans grown on cultures in YPD at pH 7.4 at $37{ }^{\circ} \mathrm{C}$ were named Trans EV. Our results showed a heterogeneous EV distribution profile within these conditions, and the majority of EVs obtained from yeast to hyphae transition cultures (Trans EV) had a range size from 99 to $182 \mathrm{~nm}$ and minor populations with sizes

176 varying from 23 to $85 \mathrm{~nm}$ and 232 to $440 \mathrm{~nm}$. For EVs isolated from C. albicans yeast

177 cultures (Control EV), the majority of EVs had a range size from 107 to $154 \mathrm{~nm}$, and a

178 minor population in the range of 211 to $440 \mathrm{~nm}$. Previous studies have demonstrated the heterogeneity of EVs from Candida spp., showing a distribution profile with population

180 sizes ranging from 60 to $280 \mathrm{~nm}$, and in C. albicans, the sizes varied from $100 \mathrm{~nm}$ to up $600 \mathrm{~nm}[5,38,39]$.

We also evaluated the gene expression profiles of selected genes ( $h w p 1$, sap5, cht2, and sec24) during $C$. albicans growth in yeast to hyphae transition cultures in comparison to yeast cultures after different incubation times, such as $0.5,1,2$, and $4 \mathrm{~h}$ (S2 Fig). These genes were previously modulated in microarray data of C. albicans

186 grown as hyphae with serum at $37^{\circ} \mathrm{C}$, and sap5 ("secreted aspartyl protease") and $h w p 1$

187 (“cell wall protein hyphal wall protein 1") were highly upregulated [40]. We identified a time-dependent modulation for the genes $\operatorname{cht} 2$ and $\sec 24$, with a significant 
Extracellular Vesicles as communication mediators in fungi

191 Taking advantage of this information, we compared gene expression profiles after EVs

192 uptake in C. albicans. Thus, the C. albicans cells were incubated with Trans EV or

193 Control EV (Fig 4 A). Thereafter, the cells were recovered through centrifugation and

194 resuspended in a yeast to hyphae medium. By analyzing the morphological features of

195 C. albicans in yeast-to-hyphae condition assessed throughout the incubation time

196 points, we identified the occurrence of the three main morphologies presented by $C$.

197 albicans, yeast, pseudo-hyphae, and hyphae. Our results also showed a possible increase

198 in cellular proliferation after EVs uptake compared to no EV uptake cultures. The XTT

199 assay reinforced the involvement of EVs in cell cycle regulation. (Fig 4B). Moreover,

200 the culture that underwent Trans-EV uptake appeared to present changes in yeast

201 development, in which a particular cellular clumping was detected even at earlier time

202 points (Fig 4C).

203 EV uptake caused a rapid response toward hypha-inducing stimuli, with a more

204 significant upregulation of the $h w p l$ gene at an earlier incubation time point (1h)

205 followed by a decay in its transcript levels at a later time point (4h), which was

206 observed for both uptake conditions, Control EV and Trans EV (Figs 5 A and 5 E). The

207 transition panel (S2 Fig) suggested a fluctuation in the $h w p 1$ modulation, with a higher

208 increase in the transcript levels after $2 \mathrm{~h}$, showing an approximately 50 -fold difference.

209 In addition, the EVs from transition cultures (Trans EV) promoted repression of the

$210 \sec 24$ gene after 1 and $4 \mathrm{~h}$ (Figs 5B and 5F). The transition panel demonstrated its

211 downregulation, particularly in delayed incubation time points, in which hyphae were

212 more commonly found. In addition, the cht2 gene was repressed after EVs uptake from

213 transition cultures after $1 \mathrm{~h}$, and no change in its transcription levels was observed after

214 4h (Figs 5C and 5G). A previous study showed that the downregulation of this cht2

215 gene is a remarkable feature in hyphae [41]. Therefore, our data suggest a boost in 
Extracellular Vesicles as communication mediators in fungi

216 hyphae induction after EVs stimulation. Curiously, sap5, which is mainly upregulated

217 in cells with hyphal morphology, presented a decrease in the transcription levels in EVs

218 uptake conditions (Figs 5D and 5H).

\section{Discussion}

Intercellular communication occurs through contact with cells or by the

secretion of molecules such as quorum sensing (QS) effectors. A recent study

demonstrated that EVs enriched with Fks1 and Chs3 from Saccharomyces cerevisiae rescued the yeast cells from cell wall disturbing [42], which suggested the possibility that EVs function in fungal intra-species communication.

Herein, we evaluated whether EVs are capable of mediating intra-species pathogens. We used an uptake time of $1 \mathrm{~h}$, which was sufficient to allow the

230 incorporation of radioactive EVs in different fungal cells, as aforementioned (Fig. 1). It

231 is expected that subtle differences in EVs uptake could be responsible for altering and regulating gene expression because fungi have the refined ability to sense any change in

233 the environment and adjust their metabolism in response to these changes. agents $P$. brasiliensis and A. fumigatus. In the $P$. brasiliensis model, the genes

236 belonging to the UPR pathway were studied after cultures underwent EVs uptake (EVs obtained from previous tunicamycin-exposed cultures) in comparison to cells directly exposed to tunicamycin. The UPR pathway is switched on to re-establish Endoplasmic

239 Reticulum homeostasis by heightening the folding capability and controlling misfolded

240 protein disposal [43]. In fungi, this pathway comprises the ER-transmembrane sensor

241 Ire1/IreA (Ser/Thr kinase) and a transcription factor Hac1/HacA [44]. Our experiments 
Extracellular Vesicles as communication mediators in fungi

242 demonstrated the upregulation of both genes in EVs uptake cultures, suggesting that

243 EVs function in fungal communication.

244 In the A. fumigatus model, EVs obtained from a regular or an irradiated culture

245 triggered a stress response in fresh A. fumigatus cultures, as evidenced by colony

246 reduction formation and upregulation of a stress response gene, the $m p k C$ gene. We

247 hypothesize that fungitoxic compounds in EVs from A. fumigatus may be responsible

248 for these effects. Previously, the production of antifungal compounds by filamentous

249 fungi such as A. fumigatus was reported [45]. However, the characterization and

250 understanding of the processes mediated by EVs in A. fumigatus have been poorly

251 explored. Recently, a study showed the production and cargo description of EVs from

252 A. fumigatus, in which approximately 60 proteins were identified with potential roles in

253 immunomodulation and pathogenicity [19].

254 In this study, the uptake of EVs from cultures exposed to UV light prompted the

255 most pronounced upregulation of the $m p k C$ gene. It also promoted a remarkable

256 increase in transcript levels of the $a k u A$ gene. $a k u A$ is involved in DNA repair [46]. UV

257 exposure causes DNA damage through mutation and pyrimidine dimers and induces

258 oxidative stress status [47, 48]. A previous study demonstrated the involvement of $a k u A$

259 in cellular protection against UV radiation exposure, showing that $a k u A$ deletion was

260 responsible for a significant reduction in survival rates of the mutant strain compared to

261 A. fumigtaus wild type [49]. Moreover, we revealed that the cultures that underwent

262 EVs uptake from A. fumigatus showed a trend of downregulating an encoding gene of

263 cyclin-dependent kinase, NimA, involved in cell cycle transition [50].

In $C$. albicans, we assessed the potential of EVs to favor hyphal formation. It is

265 widely accepted that dimorphism in C. albicans is important for virulence [51]. The

266 yeast-to-hyphae transition is a tightly regulated process of sensing and responding to 
Extracellular Vesicles as communication mediators in fungi

267 environmental cues [52]. Hyphae formation is mainly associated with invasion and

268 adaptive responses during fungus-host interactions [53]. Recently, single-cell RNA-seq

269 data showed the dynamic regulation of transition genes during macrophage infection

270 with $C$. albicans and also highlighted the occurrence of bimodal modulation in genes

271 related to hyphae formation and cell wall remodeling concomitantly with differences in

272 immunomodulation responses [54].

273 In our data, we detected a new response characterized by cell clumping after

274 Trans EV uptake, in which the EVs were obtained from C. albicans hyphae-inducing

275 cultures. Cell clumping changes probably reflect changes in surface hydrophobicity.

276 This feature may result from cell surface changes activated in the regulation of hyphal

277 expansion $[55,56]$. Furthermore, the gene modulation profile assessed after EVs uptake

278 also showed a boost in yeast to hyphae transition response, mainly prompted after Trans

279 EV uptake, which is reinforced by the presence of long hyphae in this treatment (S3

280 Fig). Hyphal growth is associated with a hyphal-specific transcriptional program that

281 paves the way towards the expression of genes related to virulence traits such as

282 adhesion (ALS3 and HWP1), invasion (ALS3), oxidative stress response (SOD5),

283 proteolytic activity (SAPs), and others [53]. In a previous high-throughput study, a set

284 of genes showed differential modulation after transition stimuli, including the genes

285 sap5, hwpl, sec24, cht2 [40]. Furthermore, hyphal development relies on a complex

286 network of transduction signals that respond to environmental cues and activate the

287 molecular processes involved in driving the high polarization growth of hyphal forms

$288 \quad[57,58]$.

Aspects of cell cycle organization are also unique in hyphae compared to

290 pseudo-hyphae and yeasts. Hyphal forms showed different branching patterns,

291 regulation of the cell cycle, and polarization [58]. In addition, a phenomenon known as 
Extracellular Vesicles as communication mediators in fungi

292 QS governs responses related to hyphal formation and control of cell density [59, 60].

293 Many QS molecules might also be found within fungal EVs; however, it is also possible

294 to speculate a cross-regulation between small RNA content in EVs and QS phenomena

295 in fungi. A recent study showed the involvement of QS molecules such as farnesol

296 derivatives and medium-chain fatty acids in EVs obtained from yeast culture as

297 potential regulators of cellular proliferation and yeast-to-hyphae development [31]. The

298 EVs from C. albicans reduced the hyphae and biofilm formation, and the impact of $C$.

299 albicans EVs on invasive hyphae development and virulence, as shown in Galleria

300 mellonella model [31]. Moreover, that study was conducted exploring EVs obtained

301 from yeast cultures, and it is reasonable that the cargo and the message within this EV

302 contribute to cells remain in this form.

303 The current knowledge regarding the differences in cell cycle regulation in

304 hyphal development associated with our data prompted the investigation of cellular

305 proliferation after EVs uptake. We demonstrated that the conditions that underwent EVs

306 uptake presented an increase in mitochondrial activity, suggesting a potential function

307 of EVs in heightening cellular metabolism and/or proliferation. EVs were previously

308 shown to enhance cellular proliferation in C. albicans [31] as well as in C. neoformans

309 within macrophages. The high activation of the $C$. neoformans proliferation rate was

310 named the "division of labor" mechanism [11]. It was ascribed as an important

311 virulence trait transferred from an outbreak strain to a non-outbreak strain [11].

312 Collectively, our data pave new avenues for EVs functions in fungal intra-

313 species communication, supporting adaptive responses and virulence mechanisms.

314 Although we recognize the need to develop our knowledge about the complex cellular

315 communication circuit switched on by EVs, and regardless of how it will be addressed 
Extracellular Vesicles as communication mediators in fungi

316 in future, this study sheds new light on the role of fungal EVs in intra-species cellular

317 communication.

318

319

320

321

322

323

324

325

326

327

328 incubated for two days at $37^{\circ} \mathrm{C}$. These plates were used for the following experiments: 342 EVs isolation and communication assay.

\section{Methods}

\section{Fungal strains and growth conditions}

Paracoccidioides brasiliensis strain 18 (Pb18) was cultivated as previously described [61]. The Pb18 yeast form was maintained in Fava Netto semi-solid medium and incubated at $36^{\circ} \mathrm{C}$. Yeast growth was performed by inoculating cultures in liquid YPD medium ( $2 \%$ peptone, $1 \%$ yeast extract, and $2 \%$ glucose) at $36{ }^{\circ} \mathrm{C}$ on a rotary shaker at $100 \mathrm{rpm}$ for $72 \mathrm{~h}$. Tunicamycin (TM) was used to induce endoplasmic reticulum (ER) stress. TM $(15 \mu \mathrm{g} / \mathrm{ml})$ was prepared in $20 \mathrm{mM}$ of $\mathrm{NaOH}$, and it was added to yeast cultures in liquid YPD for 5 days at $36{ }^{\circ} \mathrm{C}$ on a rotary shaker at100 rpm to obtain EVs derived from ER-stressed fungi. The same fungal growth was performed without TM to obtain Pb18 control EVs.

The Aspergillus fumigatus strain CEA17 used in this study was grown in a complete agar malt medium [YAG medium supplemented with malt extract: $2 \%(\mathrm{w} / \mathrm{v})$ glucose, $0.2 \%(\mathrm{w} / \mathrm{v})$ yeast extract, $2 \%(\mathrm{w} / \mathrm{v})$ malt extract, $2 \%(\mathrm{w} / \mathrm{v})$ agar, and $0.1 \%$ (v/v) trace elements] for 7 days at $37^{\circ} \mathrm{C}$. Conidia suspensions were obtained from 7 day-old plates with sterilized PBS, recovered by centrifugation, and filtered through sterile Miracloth (Millipore, Billerica, MA, USA). Conidia concentration was determined using a Neubauer chamber. Approximately $1 \times 10^{3}$ conidia were directly inoculated into a complete YAG medium or the conidia suspension was first exposed to UV light for $60 \mathrm{~s}$ and then inoculated into a complete YAG medium. The cultures were 
Extracellular Vesicles as communication mediators in fungi

medium (Oxoid, Basingstoke, UK) for 72h. One fresh colony was inoculated into $10 \mathrm{ml}$

347 (150rpm). Then, the overnight cultures of $C$. albicans were diluted to an $\mathrm{OD}_{600}$ range of

$3480.100-0.130$ with YPD medium ( $\mathrm{pH}$ 6.3) or YPD medium $(\mathrm{pH} 7.4)$, and grown at $30{ }^{\circ} \mathrm{C}$

349 or $37{ }^{\circ} \mathrm{C}$, respectively. The cultures grown on YPD at $\mathrm{pH} 6.3$ represent the control

cultures, in which no stimuli for hyphae differentiation were offered, whereas cultures

by $\mathrm{pH}(7.4)$ and temperature $\left(37^{\circ} \mathrm{C}\right)$ was offered to prompt hyphae differentiation. After that, the cultures were used to perform the EVs isolation experiment, the gene expression profile of yeast to hyphae, and the communication assay.

355

356

357

358

\section{EVs isolation}

EVs from $\mathrm{Pb} 18$ yeast cultivated in the presence or absence of $\mathrm{TM}$ were isolated as previously described [62]. Yeast cultures of Pb18 growth in YPD medium were depleted from cell pellets by serial centrifugation at 5,000 $\times \mathrm{g}$ for $15 \mathrm{~min}$ and $15,000 \times \mathrm{g}$ for $30 \mathrm{~min}$ at $4{ }^{\circ} \mathrm{C}$. The supernatants, containing EVs, were concentrated and filtered using Amicon® systems (Millipore, Billerica, MA, USA) with a 100-kDa cutoff membrane. The concentrated material was centrifuged again at $15,000 \times \mathrm{g}$ for $30 \mathrm{~min}$ at $4{ }^{\circ} \mathrm{C}$, and the supernatants were centrifuged at $100,000 \times \mathrm{g}$ for $1 \mathrm{~h}$ at $4{ }^{\circ} \mathrm{C}$ to collect vesicles. The EVs pellets were resuspended in PBS for NTA analysis and experiments. EVs obtained from TM-treated Pb18 were termed TM EVs, whereas EVs obtained from non-treated cultures were termed $\mathrm{Pb}$ EVs.

Regarding the isolation of $A$. fumigatus EVs, the procedures were performed as previously described $[19,39]$, with slight modifications. 2-days-old plates obtained for a 
Extracellular Vesicles as communication mediators in fungi

370 regular culture or a UV-exposed culture were used to isolate EVs. UV light exposure

371 cultures were obtained after conidial irradiation. Approximately $10^{4}$ conidia/ml were

372 irradiated with UV germicidal light (G1578 UV lamp) at $16 \mathrm{~cm}$ distance for $60 \mathrm{~s}$ with

373 constant shaking, and then $100 \mu \mathrm{l}$ of this irradiated suspension were plated on YAG

374 medium, yielding about $10 \%$ of CFUs in comparison to non-irradiated cultures. The

375 cells were washed twice with $3 \mathrm{ml}$ of sterile PBS, recovered from the dish plates with

376 inoculation loops, and then transferred to centrifuge tubes. Thereafter, the cell

377 suspension was filtered through sterile Miracloth (Millipore, Billerica, MA, USA), and

378 then a sequential centrifugation and supernatant concentration in the Amicon system

379 was performed. The EVs obtained from UV light exposure were named UV EV,

380 whereas the EVs obtained from regular cultures were called Control EV.

381 Isolation of $C$. albicans EVs was performed as described previously, with slight

382 modifications [9, 42]. The concentration of the $C$. albicans cultures was adjusted as

383 mentioned above, and the preinocula were added into $300 \mathrm{ml}$ of YPD (pH 6.3) or YPD

384 (pH 7.4), and incubated for $4 \mathrm{~h}$ at $30{ }^{\circ} \mathrm{C}$ or $37{ }^{\circ} \mathrm{C}$, with shaking (100 rpm). For EVs

385 isolation, the cells and debris were removed by sequential centrifugation at $4000 \times \mathrm{g}$ for

$38615 \mathrm{~min}$ and $15,000 \times \mathrm{g}$ for $15 \mathrm{~min}$. Supernatants were concentrated using an Amicon

387 ultra-concentration system (cutoff $100 \mathrm{kDa}$, Millipore, Billerica, MA, USA). The

388 resulting concentrated supernatant was ultracentrifuged at $100,000 \times \mathrm{g}$ for $1 \mathrm{~h}$ at $4{ }^{\circ} \mathrm{C}$.

389 Pellets were collected and resuspended in ultra-pure water (Sigma-Aldrich, St. Louis,

390 MO, USA) supplemented with protease inhibitor cocktail 10X (Sigma) $(0.2 \% \mathrm{v} / \mathrm{v})$, and

391 stored at $-80{ }^{\circ} \mathrm{C}$. Taking into account the culture conditions used to promote yeast-to-

392 hyphae transition (YPD medium at $\mathrm{pH} 7.4$, and incubated at $37^{\circ} \mathrm{C}$ ), an additional step

393 was included, in which the cultures were first filtered using sterile Miracloth (Millipore,

394 Billerica, MA, USA), and then subjected to differential centrifugation. EVs obtained 
Extracellular Vesicles as communication mediators in fungi

395

396

397

398 counting.

after $C$. albicans grown on YPD at $\mathrm{pH} 6.3$ at $30{ }^{\circ} \mathrm{C}$ were named as Control EV, while EVs obtained from C. albicans grown on YPD at $\mathrm{pH} 7.4$ and incubated at $37^{\circ} \mathrm{C}$ were named Trans EV.

\section{Nanoparticle-Tracking Analysis (NTA)}

To determine the size distribution and quantification of EVs isolated from $C$. albicans cultures in two different stages, a yeast culture condition (Control EV) and a yeast-to-hyphae culture condition (Trans EV), NTA analyses were performed. We also performed the NTA analysis to measure and characterize the size distribution of EVs isolated from regular and UV-exposed A. fumigatus cultures. We obtained the EV profiles of $P$. brasiliensis EVs, as previously described [34].NTA analysis was performed using a Nanosight appliance NS300 (Malvern Instruments, Malvern, UK) with NTA 3.0. The NTA analysis is an optical dispersion technique employed to measure the size distribution of particles in a solution at the nanometer scale [63].

\section{Determination of EVs Uptake by yeast cells.}

To obtain radiolabeled EVs, each one of the fungal species (P. brasiliensis, A. fumigatus, and C. albicans) was pulsed with $\left[1{ }^{14} \mathrm{C}\right]$ palmitic acid for $72 \mathrm{~h}$ before EVs isolation [64]. The culture medium used for each species, and EVs isolation process were described above. Radiolabeled EVs from the same species $\left(10^{9} / \mathrm{ml}\right)$ were added to the corresponding yeast phase fungi $\left(10^{7} / \mathrm{ml}\right)$ and incubated for $0,1,6,12$, and $24 \mathrm{~h}$ at 37 ${ }^{\circ} \mathrm{C}$ in $9.5 \% \mathrm{CO}_{2}$. After incubation, fungal cells were washed in PBS and lysed in $200 \mu \mathrm{l}$ of $25 \mathrm{mM}$ deoxycholate, and the resultant material was collected for scintillation 
Extracellular Vesicles as communication mediators in fungi

421 previously described. It was added to $5 \mathrm{ml}$ of YPD ( $\mathrm{pH} 6.3$ ) and incubated for $0.5,2$,

extraction. Alike, the $C$. albicans inoculum was also added to $5 \mathrm{ml}$ of YPD (pH 7.4) and

incubated for $0.5,2$, and $4 \mathrm{~h}$ at $37{ }^{\circ} \mathrm{C}$ (hyphae- yeast culture condition). The pellet obtained from these cultures was stored at $-80{ }^{\circ} \mathrm{C}$ until RNA extraction. We used the

resulting material to create a panel that reflects the expression profiles of $h w p l$, sec 24 ,

sap5, and cht2 genes during the C. albicans transition stage.

Communication assay mediated by EVs

Effect of EV on $P$. brasiliensis endoplasmic reticulum stress. The $P$.

brasiliensis yeast cells were treated with TM, as previously described [35]. The EVs

BHI medium (Sigma). RNA isolation, cDNA synthesis, and qPCR assays were performed as described previously [35].

Effects of EV on A. fumigatus UV stress. This assay was performed with $5 \mathrm{ml}$ incubated with $5 \times 10^{8} \mathrm{EVs} / \mathrm{ml}$ obtained from A. fumigatus regular cultures or UV light-

440 exposed cultures. The uptake was performed for $1 \mathrm{~h}$ at $37{ }^{\circ} \mathrm{C}$ in PBS with shaking (100

$441 \mathrm{rpm})$. Therefore, the fungal cells were recovered by centrifugation at $4000 \times \mathrm{g}$ for 10

$442 \mathrm{~min}$ at room temperature and the cultures were resuspended in $5 \mathrm{ml}$ of PBS.

443 Subsequently, approximately $100 \mu 1$ of conidia were plated on the YAG medium. After 444 incubation at $37{ }^{\circ} \mathrm{C}$ in the dark for 2 days, the CFUs were counted. CFUs from conidia 
Extracellular Vesicles as communication mediators in fungi

445 without EV uptake were counted as controls. The colonies were stored at $-80{ }^{\circ} \mathrm{C}$ until

446 RNA extraction.

$447 \quad$ Effects of EV on C. albicans dimorphism. About $5 \times 10^{8} \mathrm{EV}$ s obtained from $C$.

448 albicans yeast cultures or $C$. albicans yeast-to-hyphae transition cultures were added

449 into a fresh culture of $C$. albicans with the cell density adjusted to an $\mathrm{OD}_{600}$ of 0.100 -

4500.130 , as previously mentioned, in $5 \mathrm{ml}$ of YPD ( $\mathrm{pH} 6.3$ for $1 \mathrm{~h}$ at $30{ }^{\circ} \mathrm{C}$ ), with shaking

451 (100 rpm). The yeast cells were then recovered by centrifugation. The pellets were then

452 resuspended in $5 \mathrm{ml}$ of YPD pH 6.3 and incubated for $1 \mathrm{~h}$ and $4 \mathrm{~h}$ at $30{ }^{\circ} \mathrm{C}$ with shaking

453 (100 rpm). Alike, the pellets were also resuspended in $5 \mathrm{ml}$ of YPD (pH 7.4) and

454 incubated for $1 \mathrm{~h}$ and $4 \mathrm{~h}$ at $37^{\circ} \mathrm{C}$ under shaking (100rpm). After incubation, the cultures

455 were centrifuged at $4000 \times \mathrm{g}$ for $10 \mathrm{~min}$ at $4{ }^{\circ} \mathrm{C}$, and the pellet was stored at $-80{ }^{\circ} \mathrm{C}$ until

456 RNA extraction. Similar conditions were employed to analyze cellular proliferation

457 through the 2.3-bis (2-methoxy-4-nitro-5-sulfophenyl)-5-[carbonyl (phenylamino)]-2H-

458 tetrazolium hydroxide (XTT) reduction assay. The XTT assay was performed as

459 previously described [65] with slight modifications. After the uptake of EVs in $C$.

460 albicans cultures, the yeast pellets were recovered through centrifugation at $4000 \times \mathrm{g}$

461 for $10 \mathrm{~min}$ at room temperature, and the pellets were resuspended in YPD (pH7.4) and

462 incubated for $2 \mathrm{~h}$ at $37^{\circ} \mathrm{C}$. Then, the medium was removed, and the pellet was

463 resuspended in XTT solution ( $1 \mathrm{mg} / \mathrm{ml}$ in PBS) and menadione (1 $\mathrm{mM}$ in acetone), and

464 incubated for $3 \mathrm{~h}$ with gentle shaking. The activity of the yeast mitochondrial

465 dehydrogenase reduces the tetrazolium salt XTT to formazan salts, which results in a

466 colorimetric change that might correlate with cell viability. Colorimetric changes were

467 measured using an ELISA microplate reader (MULTISKAN FC, Thermo Scientific) at

$468450 \mathrm{~nm}$. Additionally, we followed the changes in yeast-to-hyphae transition in $C$.

469 albicans cultures after EVs uptake by microscopy analysis. Images were obtained using 
Extracellular Vesicles as communication mediators in fungi

470

471

472

473

474

475

476

477

478

479

480

481

482

483

484

485

486

487

488

489

490

491

492

493

494

495

Zeiss Observer Z.1 microscope with AxioVision SE64 software after 1h, 2h, and 4h time points. As controls, cultures that had not undergone the EVs uptake process were analyzed.

\section{RNA extraction and quantitative real time PCR (RT-qPCR)}

The C. albicans cells were treated with lysis solution $(20 \mathrm{mg} / \mathrm{ml}$ lysozyme, 0.7 $\mathrm{M} \mathrm{KCl}$, and $1 \mathrm{M} \mathrm{MgSO} 4, \mathrm{pH}$ 6.8) for $1 \mathrm{~h}$ with shaking (100 rpm). Next, the supernatant was removed by centrifugation at $1000 \times g$ for $10 \mathrm{~min}$, and total RNA was extracted using the Illustra RNAspin Mini RNA Isolation Kit (GE Healthcare), following the manufacturer's instructions. The A. fumigatus mycelia were lysed by mechanical pulverization with a pestle and mortar in liquid nitrogen, and total RNA extraction was performed using Illustra RNAspin Mini RNA Isolation Kit (GE Healthcare). $P$. brasiliensis cells were also lysed with the aid of a small mortar and pestle in liquid nitrogen before total RNA was isolated using Trizol reagent (Life Technologies, Carlsbad, CA, USA), as described previously [35]. RNA concentration and quality were estimated using a nanophotometer (Implem). The RNA was pretreated with DNase (Sigma). Complementary DNA (cDNA) synthesis was performed using the HighCapacity cDNA Reverse Transcription kit (Applied Biosystems) following the manufacturer's instructions. Quantitative RT-PCR was conducted as described previously [66]. The qPCR experiments were performed with SYBR Green Master Mix (Applied Biosystems) in the Step One Plus platform. Primer sequences were retrieved from the IDT DNA “primer quest” tool (www. idtdna. com/ primerquest/Home/ Index), and the oligonucleotide sequences are listed in Table 1. The algorithm used for gene expression analysis was the relative quantification $2^{-\Delta \Delta \mathrm{Ct}}$ method [67], and graphs were generated using GraphPad Prism v.5 software (GraphPad). 
bioRxiv preprint doi: https://doi org/10.1101/2021.06.03,447024; this version posted June 5,2021 . The copyright holder for this preprint (which was not certified by peer review) is the author/funder, who has granted bioRxiv a license to display the preprint in perpetuity. It is made available under aCC-BY-NC-ND 4.0 International license.

Extracellular Vesicles as communication mediators in fungi

496

497

498 Table 1. Set of primers used in RT-qPCR

\begin{tabular}{|c|c|c|c|}
\hline Gene Id & Sequence 5'-3' & $\begin{array}{l}\text { Concentration } \\
\quad(\mathrm{nM})\end{array}$ & Efficience $(\%)$ \\
\hline RPP2B & $\begin{array}{l}\text { FWD: TGGTGTTGAAGCCGAAGAA } \\
\text { REV: CGGATGGGACAGAAGCTAAT }\end{array}$ & 100 & 95.18 \\
\hline TDH3 & $\begin{array}{l}\text { FWD: CACGGTAGATACAAGGGTGAAG } \\
\text { REV: GGAATGTTAGCTGGGTCTCTTT }\end{array}$ & 150 & 108.6 \\
\hline HWP1 & $\begin{array}{l}\text { FWD: GCCTGATGACAATCCTCCTATT } \\
\text { REV: GAGTAGTAGCTGGAGTTGTTGG }\end{array}$ & 400 & 97.75 \\
\hline CHT2 & $\begin{array}{l}\text { FWD: TGGTGGTGTTGGTGACTATG } \\
\text { REV: CAGCGTCATCAAATGGTCTTTC }\end{array}$ & 300 & 92.49 \\
\hline SAP5 & $\begin{array}{l}\text { FWD: GCGAAGCTACCGAGTTTGAT } \\
\text { REV: GCTTCAGCAGAGTTAAGGTAGAG }\end{array}$ & 500 & 100.53 \\
\hline SEC24 & $\begin{array}{l}\text { FWD: GAGCTGGATATGGCGGATATG } \\
\text { REV: GTGGAAGGTCCCTTGATAAGTC }\end{array}$ & 300 & 99.62 \\
\hline $18 \mathrm{~S}$ & $\begin{array}{l}\text { FWD: AAGTGCGCGGCAATAACA } \\
\text { REV: CTCGGCCAAGGTGATGTACT }\end{array}$ & 100 & 89.34 \\
\hline Btub & $\begin{array}{l}\text { FWD: TTCCCAACAACATCCAGACC } \\
\text { REV: CGACGGAACATAGCAGTGAA }\end{array}$ & 70 & 119 \\
\hline$a k u A$ & $\begin{array}{l}\text { FWD: GCTCCTGTGTACCTGAAAGATG } \\
\text { REV: GGGACCGACCGAGAATTTATG }\end{array}$ & 70 & 100.74 \\
\hline$m p k C$ & $\begin{array}{l}\text { FWD: TTCCGAGGTCCTTGACTATCT } \\
\text { REV: GTTCAAGAGCACTCGGATCAA }\end{array}$ & 100 & 105.13 \\
\hline $\operatorname{nim} A$ & $\begin{array}{l}\text { FWD: TCAGCGGCAAGCAAGAATA } \\
\text { REV: TGAGGGAAGATCGGGTATATCA }\end{array}$ & 100 & 92.65 \\
\hline PbHACA & $\begin{array}{l}\text { FWD: GATTCACCCACTCTTGTCCC } \\
\text { REV: GAATCTGTGAGGTCCAAGTCC }\end{array}$ & 100 & 97.38 \\
\hline PbIRE1 & $\begin{array}{l}\text { FWD: CACAATTTACAGGAGCTTGCG } \\
\text { REV: GAACCCTTGTCTCGTCTAACTC }\end{array}$ & 100 & 95.43 \\
\hline A-tubulin & $\begin{array}{l}\text { FWD: CGGCTAATGGAAAATACATGGC } \\
\text { REV: GTCTTGGCCTTGAGAGATGCAA }\end{array}$ & 100 & 93.12 \\
\hline
\end{tabular}

499

500

501 Statistical analyses

502 The results are presented as mean values from independent experimental \pm

503 standard deviations. Significant differences were determined by one-way analysis of

504 variance followed by Tukey's post hoc tests or by unpaired t-test, using the GraphPad

505 Prism 5 software.

506

507 Author Contributions 
Extracellular Vesicles as communication mediators in fungi

508 FA, OH, AC, MR, and TB conceived the study. FA, OH, and TAB. performed the 509 experimental design and laboratory experiments. AP, and MSF contributed with A.

510 fumigatus assays. AP and PS performed the illustrative designs. GT assisted in the $C$.

511 albicans $\mathrm{EV}$ s isolation assay. TB, NM, AR, AC, LA, MR and FA wrote the manuscript.

\section{FUNDING}

514 This work was supported by grants from the Brazilian Agencies: São Paulo Research

515 Foundation - FAPESP [proc. No. 2016/03322-7, proc. No. 2019/22596-9 and

516 Fellowship No. 2019/02504-2 to A.M.P, and Fellowship No. 2019/22454-0 to M.S.F.];

517 National Council for Scientific and Technological Development - CNPq [Grants No.

518 420670/2018-1], Coordenação de Aperfeiçoamento de Pessoal de Nível Superior

519 (CAPES); and Fundação de Apoio ao Ensino, Pesquisa e Assistência -FAEPA.

\section{ACKNOWLEDGMENTS}

522 We thank Carlos Alberto Vieira for technical support.

\section{Figure Captions}

Fig 1. Evaluation of Extracellular Vesicles (EVs) uptake in different fungal species.

The absorption of radioactive VEs was evaluated after $0 \mathrm{~h}, 1 \mathrm{~h}, 6 \mathrm{~h}, 12 \mathrm{~h}$ and $24 \mathrm{~h}$ in the

following yeast cells: P. brasiliensis (A), A. fumigatus (B) and C. albicans (C).

Fig 2. EVs from $P$. brasiliensis as cellular communicator during ER stress.

Schematic representation of EVs obtained after tunicamycin exposure (A). The relative

expression of UPR belonging genes IREI (B) and HACA (C) were determined after EVs

uptake. Significantly different values are indicated by asterisks as determined using

ANOVA followed by Tukey's post hoc test $(\mathrm{P}<0.05)$. The calibrator was PBS condition and the positive control was tunicamycin (TM).

534 Fig 3. EVs from $\boldsymbol{A}$. fumigatus as stress message effectors. Schematic representation of EVs obtained from regular cultures, without UV exposed (Control EV), and EVs

light exposure. The colony formation was counted and a percent of reduction was

538 determined after EVs uptake (B). RT-qPCR for A. fumigatus genes mpkC (C), akuA (D)

539 and $\operatorname{nimA}(\mathrm{E})$. Relative expression was assessed using NO EV uptake condition as 
Extracellular Vesicles as communication mediators in fungi

540 reference sample, and $18 \mathrm{~S}$ and $\beta t u b$ as reference of normalization. Significantly

541 different values are indicated by asterisks as determined using ANOVA followed by

542 Tukey's post hoc test $(* \mathrm{P}<0.05, * * \mathrm{P}<0.01, * * * \mathrm{P}<0.001)$.

543 Fig 4. EVs heighten the cellular proliferation in $C$. albicans. Schematic

544 representation of EVs obtained from yeast cultures (Control EV) and yeast to hyphae

545 cultures (Trans EV) (A). XTT reduction assay to assess cellular proliferation after EVs

546 uptake during $2 \mathrm{~h}$ of growth on transition cultures (B). Morphological appearance

547 addressed by microscope images of $C$. albicans cells grown on YPD pH 7.4 at $37^{\circ} \mathrm{C}$

548 after EVs uptake (C).

549 Fig 5. EVs prompted a boost in yeast to hyphae transition gene expression

550 response. $\mathrm{RT}$-qPCR evaluated a set of $C$. albicans genes after EVs uptake during $1 \mathrm{~h}$

551 and $4 \mathrm{~h}$ of growth on transition cultures. hwpl (A and E), sec24 (B and F), cht2 (C and

$552 \mathrm{G})$ and sap5 (D and H). The relative expression was assessed using NO EV uptake

553 condition as the reference sample after normalization with the $r p p 2 b$ and $t d h 3$ genes.

554 Significantly different values are indicated by asterisks, determined using ANOVA

555 followed by Tukey's post hoc test $(\mathrm{P}<0.05, * * \mathrm{P}<0.01, * * * \mathrm{P}<0.001)$.

556

557 Supplementary Content:

559 S1 Fig. Histograms from particle-size distribution of extracellular vesicles (EVs) from

560 C. albicans and A. fumigatus for each assessed condition.

561 S2 Fig. Transition gene expression profile in C. albicans for selected genes such as

$562 h w p 1, \sec 24, \operatorname{cht} 2$, and sap5 after 0.5, 2, and 4h. Control cultures were used as reference

563 for the modulation of transition cultures. The rpp $2 b$ and $t d h 3$ genes were used as 
Extracellular Vesicles as communication mediators in fungi

564 normalizer genes. Significantly different values are indicated by asterisks, as

565 determined using an unpaired t-test $(* \mathrm{P}<0.05)$.

566 S3 Fig. Morphological traits evaluated after EV treatment at $4 \mathrm{~h}$ in yeast to hyphae

567 transition condition. The fungal forms were examined by optical microscopy. Control

568 with No EV (A), treatment with Control EV (B) and treatment with Trans EV (C).

569 Hyphae are shown by blue arrows and pseudo-hyphae are represented by black arrows.

\section{References}

572

573 1. Almeida F, Rodrigues ML, Coelho C. The still underestimated problem of fungal

574 diseases worldwide. Front Microbiol. 2019;10:214. Epub 2019/02/28. doi:

575 10.3389/fmicb.2019.00214. PubMed PMID: 30809213; PubMed Central PMCID:

576 PMCPMC6379264.

$577 \quad 2 . \quad$ Brown GD, Denning DW, Gow NA, Levitz SM, Netea MG, White TC. Hidden killers:

578 human fungal infections. Sci Transl Med. 2012;4(165):165rv13. PubMed PMID: 23253612.

$5793 . \quad$ Rodrigues ML, Nimrichter L, Oliveira DL, Frases S, Miranda K, Zaragoza O, et al.

580 Vesicular polysaccharide export in Cryptococcus neoformans is a eukaryotic solution to the

581 problem of fungal trans-cell wall transport. Eukaryot Cell. 2007;6(1):48-59. Epub 2006/11/23.

582 doi: EC.00318-06 [pii]

583 10.1128/EC.00318-06. PubMed PMID: 17114598.

584 4. Ikeda MAK, de Almeida JRF, Jannuzzi GP, Cronemberger-Andrade A, Torrecilhas

585 ACT, Moretti NS, et al. Extracellular Vesicles From Sporothrix brasiliensis Are an Important

586 Virulence Factor That Induce an Increase in Fungal Burden in Experimental Sporotrichosis.

587 Front Microbiol. 2018;9:2286. Epub 2018/10/20. doi: 10.3389/fmicb.2018.02286. PubMed

588 PMID: 30333803.

5895 5. Vargas G, Rocha JD, Oliveira DL, Albuquerque PC, Frases S, Santos SS, et al.

590 Compositional and immunobiological analyses of extracellular vesicles released by Candida

591 albicans. Cell Microbiol. 2015;17(3):389-407. Epub 2014/10/08. doi: 10.1111/cmi.12374.

592 PubMed PMID: 25287304.

593 6. Gehrmann U, Qazi KR, Johansson C, Hultenby K, Karlsson M, Lundeberg L, et al.

594 Nanovesicles from Malassezia sympodialis and host exosomes induce cytokine responses--

595 novel mechanisms for host-microbe interactions in atopic eczema. PLoS One.

596 2011;6(7):e21480. Epub 2011/07/30. doi: 10.1371/journal.pone.0021480

597 PONE-D-11-04392 [pii]. PubMed PMID: 21799736.

5987 7. Albuquerque PC, Nakayasu ES, Rodrigues ML, Frases S, Casadevall A, Zancope-

599 Oliveira RM, et al. Vesicular transport in Histoplasma capsulatum: an effective mechanism for

600 trans-cell wall transfer of proteins and lipids in ascomycetes. Cell Microbiol. 2008;10(8):1695-

601 710. Epub 2008/04/19. doi: CMI1 160 [pii]

602 10.1111/j.1462-5822.2008.01160.x. PubMed PMID: 18419773.

603 8. Oliveira DL, Nakayasu ES, Joffe LS, Guimaraes AJ, Sobreira TJ, Nosanchuk JD, et al.

604 Characterization of yeast extracellular vesicles: evidence for the participation of different

605 pathways of cellular traffic in vesicle biogenesis. PLoS One. 2010;5(6):e11113. Epub

606 2010/06/19. doi: 10.1371/journal.pone.0011113. PubMed PMID: 20559436.

607 9. Vallejo MC, Matsuo AL, Ganiko L, Medeiros LC, Miranda K, Silva LS, et al. The

608 pathogenic fungus Paracoccidioides brasiliensis exports extracellular vesicles containing highly 609 immunogenic alpha-Galactosyl epitopes. Eukaryot Cell. 2011;10(3):343-51. Epub 2011/01/11. 
bioRxiv preprint doi: https://doi.org/10.1101/2021.06.03.447024; this version posted June 5,2021 . The copyright holder for this preprint (which was not certified by peer review) is the author/funder, who has granted bioRxiv a license to display the preprint in perpetuity. It is made available under aCC-BY-NC-ND 4.0 International license.

Extracellular Vesicles as communication mediators in fungi

610 doi: 10.1128/EC.00227-10. PubMed PMID: 21216942; PubMed Central PMCID:

611 PMCPMC3067469.

612 10. Leone F, Bellani L, Muccifora S, Giorgetti L, Bongioanni P, Simili M, et al. Analysis of

613 extracellular vesicles produced in the biofilm by the dimorphic yeast Pichia fermentans. J Cell

614 Physiol. 2017;233(4):2759-67. Epub 2017/03/04. doi: 10.1002/jcp.25885. PubMed PMID:

61528256706.

616 11. Bielska E, Sisquella MA, Aldeieg M, Birch C, O'Donoghue EJ, May RC. Pathogen-

617 derived extracellular vesicles mediate virulence in the fatal human pathogen Cryptococcus

618 gattii. Nat Commun. 2018;9(1):1556. Epub 2018/04/21. doi: 10.1038/s41467-018-03991-6.

619 PubMed PMID: 29674675; PubMed Central PMCID: PMCPMC5908794.

620 12. Peres da Silva R, Longo LGV, Cunha J, Sobreira TJP, Rodrigues ML, Faoro H, et al.

621 Comparison of the RNA Content of Extracellular Vesicles Derived from Paracoccidioides

622 brasiliensis and Paracoccidioides lutzii. Cells. 2019;8(7). Epub 2019/07/26. doi: cells8070765

623 [pii]

624 10.3390/cells8070765. PubMed PMID: 31340551.

625 13. Lavrin T, Konte T, Kostanjsek R, Sitar S, Sepcic K, Prpar Mihevc S, et al. The

626 Neurotropic Black Yeast Exophiala dermatitidis Induces Neurocytotoxicity in Neuroblastoma

627 Cells and Progressive Cell Death. Cells. 2020;9(4). Epub 2020/04/17. doi: cells9040963 [pii]

628 10.3390/cells9040963. PubMed PMID: 32295162.

629 14. Silva BM, Prados-Rosales R, Espadas-Moreno J, Wolf JM, Luque-Garcia JL,

630 Goncalves T, et al. Characterization of Alternaria infectoria extracellular vesicles. Med Mycol.

631 2014;52(2):202-10. Epub 2014/03/01. doi: myt003 [pii]

632 10.1093/mmy/myt003. PubMed PMID: 24576997.

633 15. Bitencourt TA, Rezende CP, Quaresemin NR, Moreno P, Hatanaka O, Rossi A, et al.

634 Extracellular Vesicles From the Dermatophyte Trichophyton interdigitale Modulate

635 Macrophage and Keratinocyte Functions. Front Immunol. 2018;9:2343. Epub 2018/10/26. doi:

636 10.3389/fimmu.2018.02343. PubMed PMID: 30356863; PubMed Central PMCID:

637 PMCPMC6190888.

638 16. Liu M, Bruni GO, Taylor CM, Zhang Z, Wang P. Comparative genome-wide analysis

639 of extracellular small RNAs from the mucormycosis pathogen Rhizopus delemar. Sci Rep.

640 2018;8(1):5243. Epub 2018/03/29. doi: 10.1038/s41598-018-23611-z

641 10.1038/s41598-018-23611-z [pii]. PubMed PMID: 29588481.

642 17. Bleackley MR, Samuel M, Garcia-Ceron D, McKenna JA, Lowe RGT, Pathan M, et al.

643 Extracellular Vesicles From the Cotton Pathogen Fusarium oxysporum f. sp. vasinfectum

644 Induce a Phytotoxic Response in Plants. Front Plant Sci. 2019;10:1610. Epub 2020/01/31. doi:

645 10.3389/fpls.2019.01610. PubMed PMID: 31998330.

646 18. de Paula RG, Antonieto ACC, Nogueira KMV, Ribeiro LFC, Rocha MC, Malavazi I, et

647 al. Extracellular vesicles carry cellulases in the industrial fungus Trichoderma reesei. Biotechnol

648 Biofuels. 2019;12:146. Epub 2019/06/22. doi: 10.1186/s13068-019-1487-7

6491487 [pii]. PubMed PMID: 31223336.

650 19. Souza JAM, Baltazar LM, Carregal VM, Gouveia-Eufrasio L, de Oliveira AG, Dias

651 WG, et al. Characterization of Aspergillus fumigatus Extracellular Vesicles and Their Effects on

652 Macrophages and Neutrophils Functions. Front Microbiol. 2019;10:2008. Epub 2019/09/26.

653 doi: 10.3389/fmicb.2019.02008. PubMed PMID: 31551957; PubMed Central PMCID:

654 PMCPMC6738167.

655 20. Brauer VS, Pessoni AM, Bitencourt TA, de Paula RG, de Oliveira Rocha L, Goldman

$656 \mathrm{GH}$, et al. Extracellular Vesicles from Aspergillus flavus Induce M1 Polarization In Vitro.

657 mSphere. 2020;5(3). Epub 2020/05/08. doi: 5/3/e00190-20 [pii]

658 10.1128/mSphere.00190-20. PubMed PMID: 32376699.

659 21. de Toledo Martins S, Szwarc P, Goldenberg S, Alves LR. Extracellular Vesicles in

660 Fungi: Composition and Functions. Curr Top Microbiol Immunol. 2018;422:45-59. Epub

661 2018/09/23. doi: 10.1007/82_2018_141. PubMed PMID: 30242512.

662 22. Rizzo J, Rodrigues ML, Janbon G. Extracellular Vesicles in Fungi: Past, Present, and

663 Future Perspectives. Front Cell Infect Microbiol. 2020;10:346. Epub 2020/08/08. doi: 
bioRxiv preprint doi: https://doi.org/10.1101/2021.06.03.447024; this version posted June 5,2021 . The copyright holder for this preprint (which was not certified by peer review) is the author/funder, who has granted bioRxiv a license to display the preprint in perpetuity. It is made available under aCC-BY-NC-ND 4.0 International license.

Extracellular Vesicles as communication mediators in fungi

664

665

666

667

668

669

670

671

672

673

674

675

676

677

678

679

680

681

682

683

684

685

686

687

688

689

690

691

692

693

694

695

696

697

698

699

700

701

702

703

704

705

706

707

708

709

710

711

712

713

714

715

10.3389/fcimb.2020.00346. PubMed PMID: 32760680; PubMed Central PMCID: PMCPMC7373726.

23. Oliveira DL, Freire-de-Lima CG, Nosanchuk JD, Casadevall A, Rodrigues ML, Nimrichter L. Extracellular vesicles from Cryptococcus neoformans modulate macrophage functions. Infect Immun. 2010;78(4):1601-9. Epub 2010/02/11. doi: IAI.01171-09 [pii] 10.1128/IAI.01171-09. PubMed PMID: 20145096.

24. Huang SH, Wu CH, Chang YC, Kwon-Chung KJ, Brown RJ, Jong A. Cryptococcus neoformans-derived microvesicles enhance the pathogenesis of fungal brain infection. PLoS One. 2012;7(11):e48570. Epub 2012/11/13. doi: 10.1371/journal.pone.0048570 PONE-D-12-24350 [pii]. PubMed PMID: 23144903.

25. Regente M, Pinedo M, San Clemente H, Balliau T, Jamet E, de la Canal L. Plant extracellular vesicles are incorporated by a fungal pathogen and inhibit its growth. J Exp Bot. 2017;68(20):5485-95. Epub 2017/11/18. doi: 4626762 [pii] 10.1093/jxb/erx355. PubMed PMID: 29145622.

26. Cai Q, Qiao L, Wang M, He B, Lin FM, Palmquist J, et al. Plants send small RNAs in extracellular vesicles to fungal pathogen to silence virulence genes. Science.

2018;360(6393):1126-9. Epub 2018/05/19. doi: science.aar4142 [pii] 10.1126/science.aar4142. PubMed PMID: 29773668.

27. Silva VKA, Rodrigues ML, May RC. Deciphering Fungal Extracellular Vesicles: From Cell Biology to Pathogenesis. Current Clinical Microbiology Reports. 2019;6(3):89-97. doi: 10.1007/s40588-019-00128-1. PubMed PMID: ISI:000482218900001.

28. Freitas MS, Bonato VLD, Pessoni AM, Rodrigues ML, Casadevall A, Almeida F. Fungal Extracellular Vesicles as Potential Targets for Immune Interventions. mSphere. 2019;4(6). Epub 2019/11/07. doi: 10.1128/mSphere.00747-19. PubMed PMID: 31694899; PubMed Central PMCID: PMCPMC6835212.

29. Voelz K, Johnston SA, Smith LM, Hall RA, Idnurm A, May RC. 'Division of labour' in response to host oxidative burst drives a fatal Cryptococcus gattii outbreak. Nat Commun. 2014;5:5194. Epub 2014/10/18. doi: ncomms6194 [pii]

10.1038/ncomms6194. PubMed PMID: 25323068.

30. Hai TP, Tuan, T. L., Anh, D. V., Mai, T. N., Huong, L. N. P., Thwaites, G. E., et al. The expression of virulence by the Cryptoccocus neoformans VNIa-5 lineage is plastic and associated with host immune background. bioRxiv. 2020. doi: 10.1101/2020.02.24.962134. 31. Honorato L, Demetrio JF, Ellis CC, Piffer A, Pereira Y, Frases S, et al. Extracellular vesicles regulate yeast growth, biofilm formation, and yeast-to-hypha differentiation in <em>Candida albicans</em>. 2021:2021.01.21.427696. doi: 10.1101/2021.01.21.427696\%J bioRxiv.

32. Brown L, Wolf JM, Prados-Rosales R, Casadevall A. Through the wall: extracellular vesicles in Gram-positive bacteria, mycobacteria and fungi. Nat Rev Microbiol.

2015;13(10):620-30. Epub 2015/09/02. doi: 10.1038/nrmicro3480. PubMed PMID: 26324094; PubMed Central PMCID: PMCPMC4860279.

33. Wolf JM, Rivera J, Casadevall A. Serum albumin disrupts Cryptococcus neoformans and Bacillus anthracis extracellular vesicles. Cell Microbiol. 2012;14(5):762-73. Epub 2012/02/01. doi: 10.1111/j.1462-5822.2012.01757.x. PubMed PMID: 22289081.

34. Hatanaka O, Rezende CP, Moreno P, Freitas Fernandes F, Oliveira Brito PKM, Martinez R, et al. Galectin-3 Inhibits Paracoccidioides brasiliensis Growth and Impacts Paracoccidioidomycosis through Multiple Mechanisms. mSphere. 2019;4(2). Epub 2019/04/26. doi: 10.1128/mSphere.00209-19. PubMed PMID: 31019001; PubMed Central PMCID: PMCPMC6483048.

35. Almeida F, Antonieto AC, Pessoni AM, Monteiro VN, Alegre-Maller AC, Pigosso LL, et al. Influence of N-glycans on Expression of Cell Wall Remodeling Related Genes in Paracoccidioides brasiliensis Yeast Cells. Curr Genomics. 2016;17(2):112-8. Epub 2016/05/27. doi: 10.2174/1389202917666151116212705. PubMed PMID: 27226767; PubMed Central PMCID: PMCPMC4864839.

36. Bruder Nascimento AC, Dos Reis TF, de Castro PA, Hori JI, Bom VL, de Assis LJ, et al. Mitogen activated protein kinases SakA(HOG1) and MpkC collaborate for Aspergillus 
bioRxiv preprint doi: https://doi.org/10.1101/2021.06.03,447024; this version posted June 5,2021 . The copyright holder for this preprint (which was not certified by peer review) is the author/funder, who has granted bioRxiv a license to display the preprint in perpetuity. It is made available under aCC-BY-NC-ND 4.0 International license.

Extracellular Vesicles as communication mediators in fungi

719 fumigatus virulence. Mol Microbiol. 2016;100(5):841-59. Epub 2016/02/16. doi:

720 10.1111/mmi.13354. PubMed PMID: 26878695.

721 37. Pereira Silva L, Alves de Castro P, Dos Reis TF, Paziani MH, Von Zeska Kress MR, Riano-Pachon DM, et al. Genome-wide transcriptome analysis of Aspergillus fumigatus exposed to osmotic stress reveals regulators of osmotic and cell wall stresses that are SakA(HOG1) and MpkC dependent. Cell Microbiol. 2016;19(4). Epub 2016/10/30. doi: 10.1111/cmi.12681. PubMed PMID: 27706915.

38. Karkowska-Kuleta J, Kulig K, Karnas E, Zuba-Surma E, Woznicka O, Pyza E, et al. Characteristics of Extracellular Vesicles Released by the Pathogenic Yeast-Like Fungi Candida glabrata, Candida parapsilosis and Candida tropicalis. Cells. 2020;9(7). Epub 2020/07/28. doi: 10.3390/cells9071722. PubMed PMID: 32708393; PubMed Central PMCID: PMCPMC7408413.

39. Reis FCG, Borges BS, Jozefowicz LJ, Sena BAG, Garcia AWA, Medeiros LC, et al. A Novel Protocol for the Isolation of Fungal Extracellular Vesicles Reveals the Participation of a Putative Scramblase in Polysaccharide Export and Capsule Construction in Cryptococcus gattii. mSphere. 2019;4(2). Epub 2019/03/22. doi: 10.1128/mSphere.00080-19. PubMed PMID: 30894430; PubMed Central PMCID: PMCPMC6429041.

40. Nantel A, Dignard D, Bachewich C, Harcus D, Marcil A, Bouin AP, et al. Transcription profiling of Candida albicans cells undergoing the yeast-to-hyphal transition. Molecular Biology of the Cell. 2002;13(10):3452-65. doi: 10.1091/mbc.E02-05-0272. PubMed PMID: ISI:000178784300008.

740 41. McCreath KJ, Specht CA, Robbins PW. Molecular cloning and characterization of 741 chitinase genes from Candida albicans. Proc Natl Acad Sci U S A. 1995;92(7):2544-8. Epub 742 1995/03/28. doi: 10.1073/pnas.92.7.2544. PubMed PMID: 7708682; PubMed Central PMCID: 743 PMCPMC42254.

744 42. Zhao K, Bleackley M, Chisanga D, Gangoda L, Fonseka P, Liem M, et al. Extracellular vesicles secreted by Saccharomyces cerevisiae are involved in cell wall remodelling. Commun Biol. 2019;2:305. Epub 2019/08/21. doi: 10.1038/s42003-019-0538-8. PubMed PMID: 31428693; PubMed Central PMCID: PMCPMC6688994.

43. Ron D, Walter P. Signal integration in the endoplasmic reticulum unfolded protein response. Nat Rev Mol Cell Biol. 2007;8(7):519-29. Epub 2007/06/15. doi: 10.1038/nrm2199. PubMed PMID: 17565364.

44. Moore KA, Hollien J. The unfolded protein response in secretory cell function. Annu Rev Genet. 2012;46:165-83. Epub 2012/09/01. doi: 10.1146/annurev-genet-110711-155644. PubMed PMID: 22934644.

45. Bladt TT, Frisvad JC, Knudsen PB, Larsen TO. Anticancer and antifungal compounds from Aspergillus, Penicillium and other filamentous fungi. Molecules. 2013;18(9):11338-76. Epub 2013/09/26. doi: 10.3390/molecules180911338. PubMed PMID: 24064454; PubMed Central PMCID: PMCPMC6269870.

46. Pannunzio NR, Watanabe G, Lieber MR. Nonhomologous DNA end-joining for repair of DNA double-strand breaks. J Biol Chem. 2018;293(27):10512-23. Epub 2017/12/17. doi: 10.1074/jbc.TM117.000374. PubMed PMID: 29247009; PubMed Central PMCID: PMCPMC6036208.

47. Ikehata H, Ono T. The mechanisms of UV mutagenesis. J Radiat Res. 2011;52(2):11525. Epub 2011/03/26. doi: 10.1269/jrr.10175. PubMed PMID: 21436607.

48. Silva-Junior AC, Asad LM, Felzenszwalb I, Asad NR. Mutagenicity induced by UVC in Escherichia coli cells: reactive oxygen species involvement. Redox Rep. 2011;16(5):187-92.

766 Epub 2011/10/19. doi: 10.1179/1351000211Y.0000000010. PubMed PMID: 22005338;

767 PubMed Central PMCID: PMCPMC6837408.

768 49. Blachowicz A, Raffa N, Bok JW, Choera T, Knox B, Lim FY, et al. Contributions of

769 Spore Secondary Metabolites to UV-C Protection and Virulence Vary in Different Aspergillus

770 fumigatus Strains. mBio. 2020;11(1). Epub 2020/02/20. doi: 10.1128/mBio.03415-19. PubMed

771 PMID: 32071276; PubMed Central PMCID: PMCPMC7029147. 
bioRxiv preprint doi: https://doi.org/10.1101/2021.06.03.447024; this version posted June 5,2021 . The copyright holder for this preprint (which was not certified by peer review) is the author/funder, who has granted bioRxiv a license to display the preprint in perpetuity. It is made available under aCC-BY-NC-ND 4.0 International license.

Extracellular Vesicles as communication mediators in fungi

50. Osmani SA, Ye XS. Cell cycle regulation in Aspergillus by two protein kinases. Biochem J. 1996;317 ( Pt 3):633-41. Epub 1996/08/01. doi: 10.1042/bj3170633. PubMed PMID: 8760343.

51. Mayer FL, Wilson D, Hube B. Candida albicans pathogenicity mechanisms. Virulence. 2013;4(2):119-28. Epub 2013/01/11. doi: 22913 [pii] 10.4161/viru.22913. PubMed PMID: 23302789.

52. Biswas S, Van Dijck P, Datta A. Environmental sensing and signal transduction pathways regulating morphopathogenic determinants of Candida albicans. Microbiol Mol Biol Rev. 2007;71(2):348-76. Epub 2007/06/08. doi: 71/2/348 [pii] 10.1128/MMBR.00009-06. PubMed PMID: 17554048.

53. Jacobsen ID, Wilson D, Wachtler B, Brunke S, Naglik JR, Hube B. Candida albicans dimorphism as a therapeutic target. Expert Review of Anti-Infective Therapy. 2012;10(1):8593. doi: 10.1586/Eri.11.152. PubMed PMID: ISI:000299013800014.

54. Munoz JF, Delorey T, Ford CB, Li BY, Thompson DA, Rao RP, et al. Coordinated host-pathogen transcriptional dynamics revealed using sorted subpopulations and single macrophages infected with Candida albicans. Nat Commun. 2019;10(1):1607. Epub 2019/04/10. doi: 10.1038/s41467-019-09599-8. PubMed PMID: 30962448; PubMed Central PMCID: PMCPMC6453965.

55. Whiteway M, Bachewich C. Morphogenesis in Candida albicans. Annu Rev Microbiol. 2007;61:529-53. Epub 2007/05/18. doi: 10.1146/annurev.micro.61.080706.093341. PubMed PMID: 17506678; PubMed Central PMCID: PMCPMC4452225.

56. Kumamoto CA. Molecular mechanisms of mechanosensing and their roles in fungal contact sensing. Nat Rev Microbiol. 2008;6(9):667-73. Epub 2008/08/06. doi: nrmicro1960 [pii] 10.1038/nrmicro1960. PubMed PMID: 18679170.

57. Sudbery P, Gow N, Berman J. The distinct morphogenic states of Candida albicans. Trends Microbiol. 2004;12(7):317-24. Epub 2004/06/30. doi: 10.1016/j.tim.2004.05.008. PubMed PMID: 15223059.

58. Sudbery PE. Growth of Candida albicans hyphae. Nat Rev Microbiol. 2011;9(10):73748. Epub 2011/08/17. doi: 10.1038/nrmicro2636. PubMed PMID: 21844880.

59. Finkel JS, Mitchell AP. Genetic control of Candida albicans biofilm development. Nat Rev Microbiol. 2011;9(2):109-18. Epub 2010/12/30. doi: nrmicro2475 [pii] 10.1038/nrmicro2475. PubMed PMID: 21189476.

60. Albuquerque P, Casadevall A. Quorum sensing in fungi--a review. Med Mycol. 2012;50(4):337-45. Epub 2012/01/25. doi: 10.3109/13693786.2011.652201. PubMed PMID: 22268493.

61. Dos Reis Almeida FB, Carvalho FC, Mariano VS, Alegre AC, Silva Rdo N, Hanna ES, et al. Influence of $\mathrm{N}$-glycosylation on the morphogenesis and growth of Paracoccidioides brasiliensis and on the biological activities of yeast proteins. PLoS One. 2011;6(12):e29216. Epub 2012/01/05. doi: 10.1371/journal.pone.0029216. PubMed PMID: 22216217; PubMed Central PMCID: PMCPMC3244461.

62. da Silva TA, Roque-Barreira MC, Casadevall A, Almeida F. Extracellular vesicles from Paracoccidioides brasiliensis induced M1 polarization in vitro. Sci Rep. 2016;6:35867. Epub 2016/10/25. doi: 10.1038/srep35867. PubMed PMID: 27775058; PubMed Central PMCID: PMCPMC5075875.

63. Rupert DLM, Claudio V, Lasser C, Bally M. Methods for the physical characterization and quantification of extracellular vesicles in biological samples. Biochim Biophys Acta Gen Subj. 2017;1861(1 Pt A):3164-79. Epub 2016/08/09. doi: 10.1016/j.bbagen.2016.07.028. PubMed PMID: 27495390. 64. Almeida F, Wolf JM, da Silva TA, DeLeon-Rodriguez CM, Rezende CP, Pessoni AM, et al. Galectin-3 impacts Cryptococcus neoformans infection through direct antifungal effects. Nat Commun. 2017;8(1):1968. Epub 2017/12/08. doi: 10.1038/s41467-017-02126-7. PubMed PMID: 29213074; PubMed Central PMCID: PMCPMC5719036.

65. Costa-Orlandi CB, Sardi JC, Santos CT, Fusco-Almeida AM, Mendes-Giannini MJ. In vitro characterization of Trichophyton rubrum and T. mentagrophytes biofilms. Biofouling. 
Extracellular Vesicles as communication mediators in fungi

826 2014;30(6):719-27. Epub 2014/05/27. doi: 10.1080/08927014.2014.919282. PubMed PMID:

82724856309.

828 66. Bitencourt TA, Oliveira FB, Sanches PR, Rossi A, Martinez-Rossi NM. The prp4

829 kinase gene and related spliceosome factor genes in Trichophyton rubrum respond to nutrients

830 and antifungals. J Med Microbiol. 2019;68(4):591-9. Epub 2019/03/23. doi:

831 10.1099/jmm.0.000967. PubMed PMID: 30900975.

832 67. Livak KJ, Schmittgen TD. Analysis of relative gene expression data using real-time

833 quantitative PCR and the 2(-Delta Delta C(T)) Method. Methods. 2001;25(4):402-8. PubMed

834 PMID: 11846609.

835 


\section{A}

P. brasiliensis

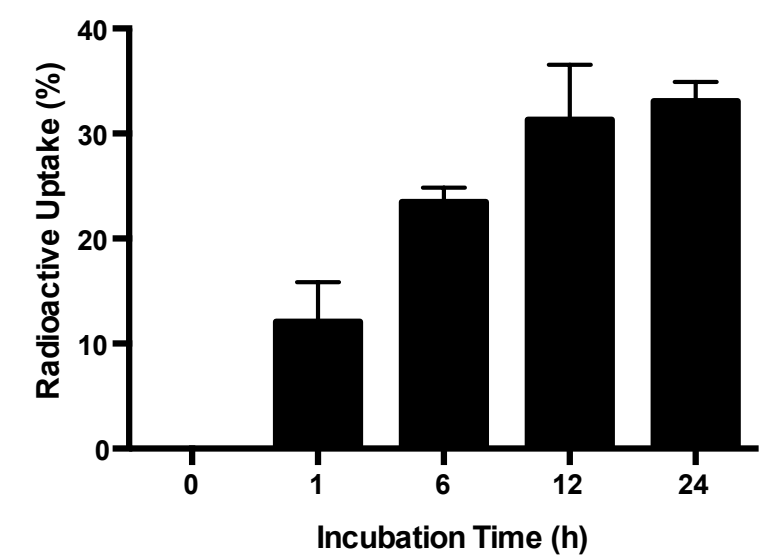

B

C

A. fumigatus

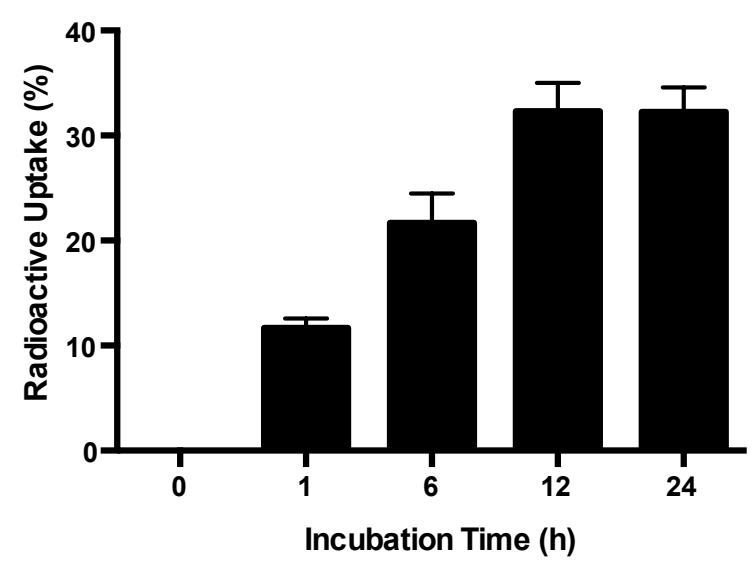

C. albicans

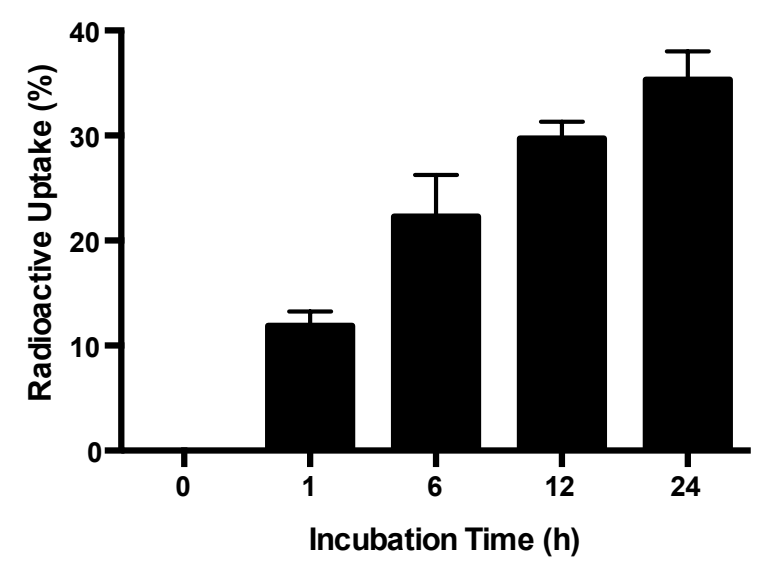


P. brasiliensis

treated with tunicamycin (TM)

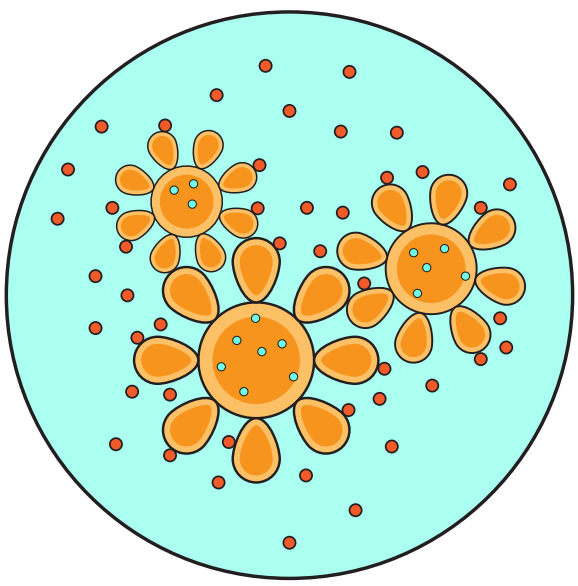

20 P. Brasiliensis

B

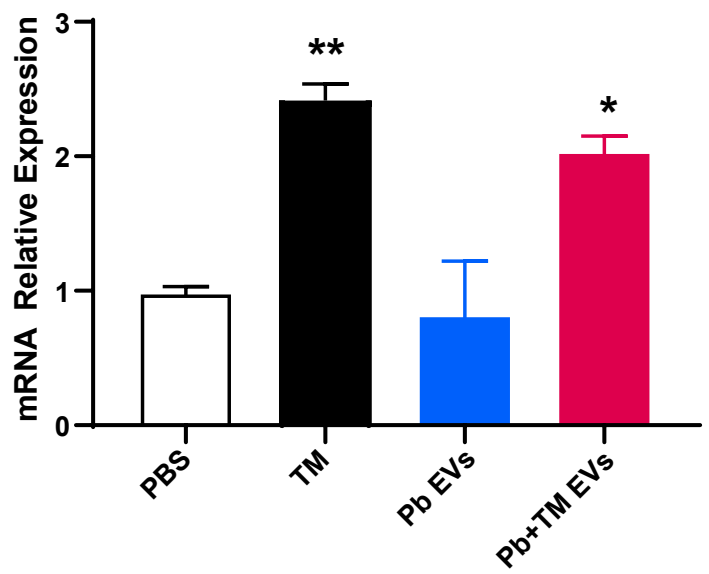

$P$. brasiliensis treated with EVs derived from previous step

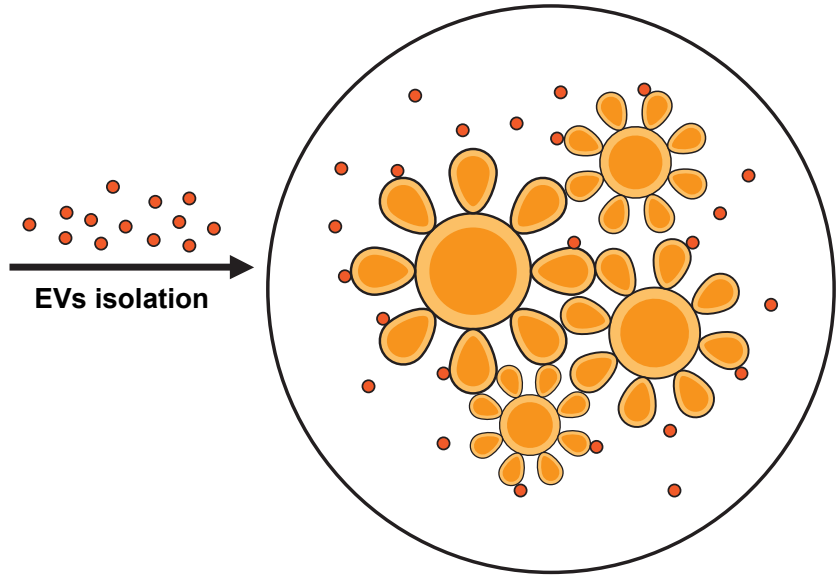

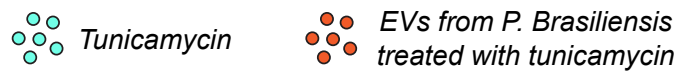

C

\section{PbIRE1}

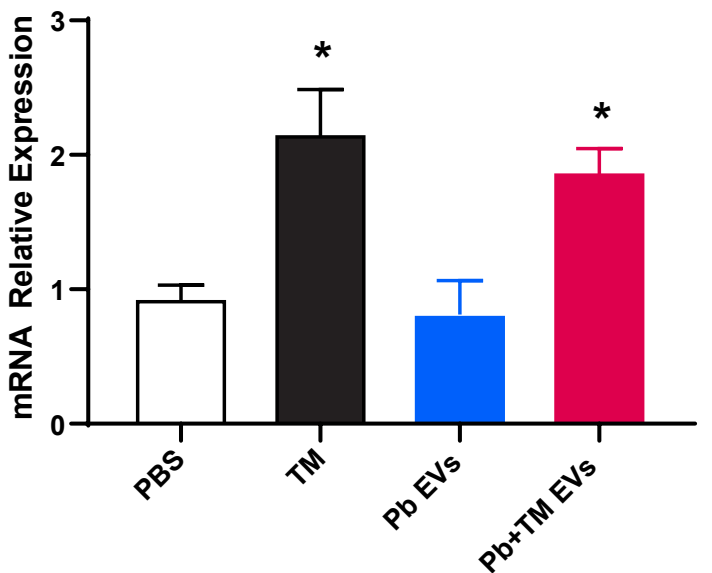


A

Control EVs

UV EVs

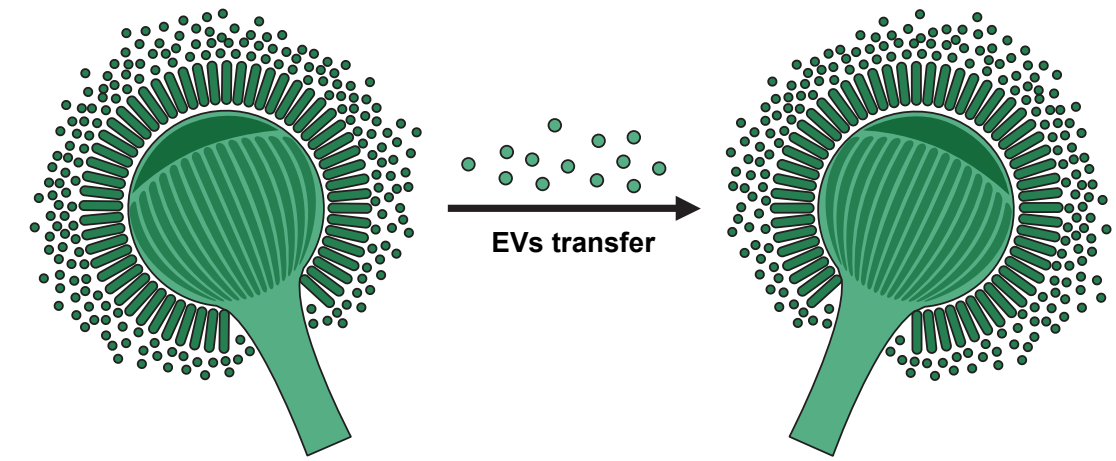

B

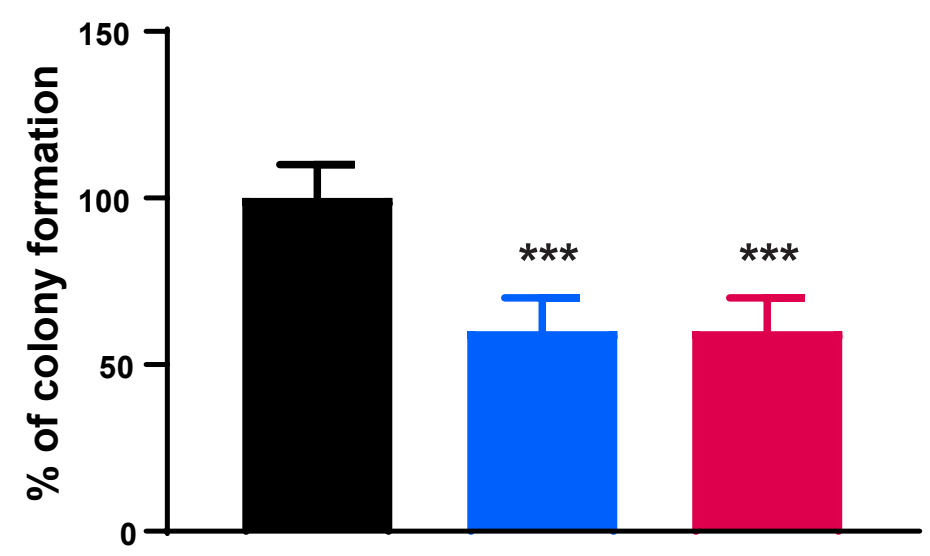

D

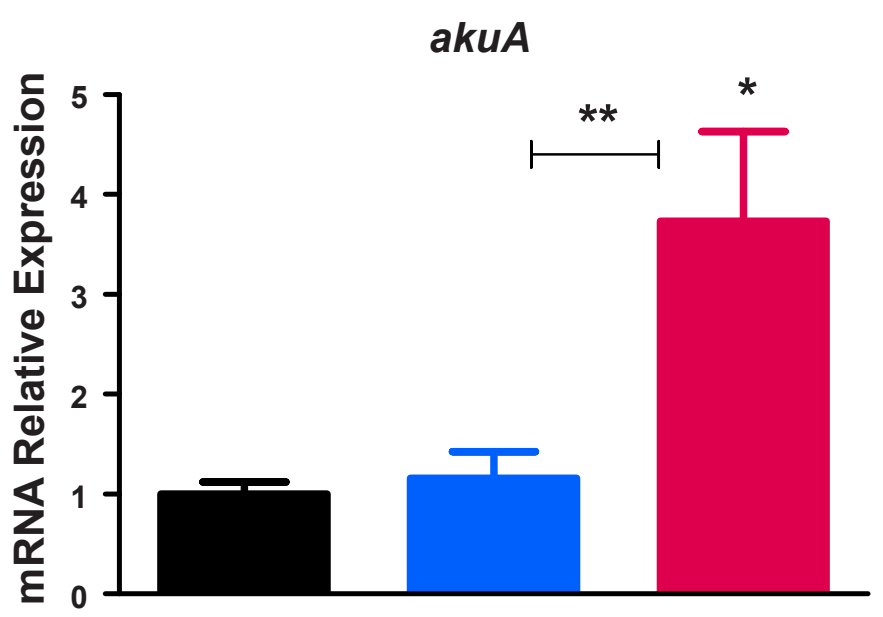

C

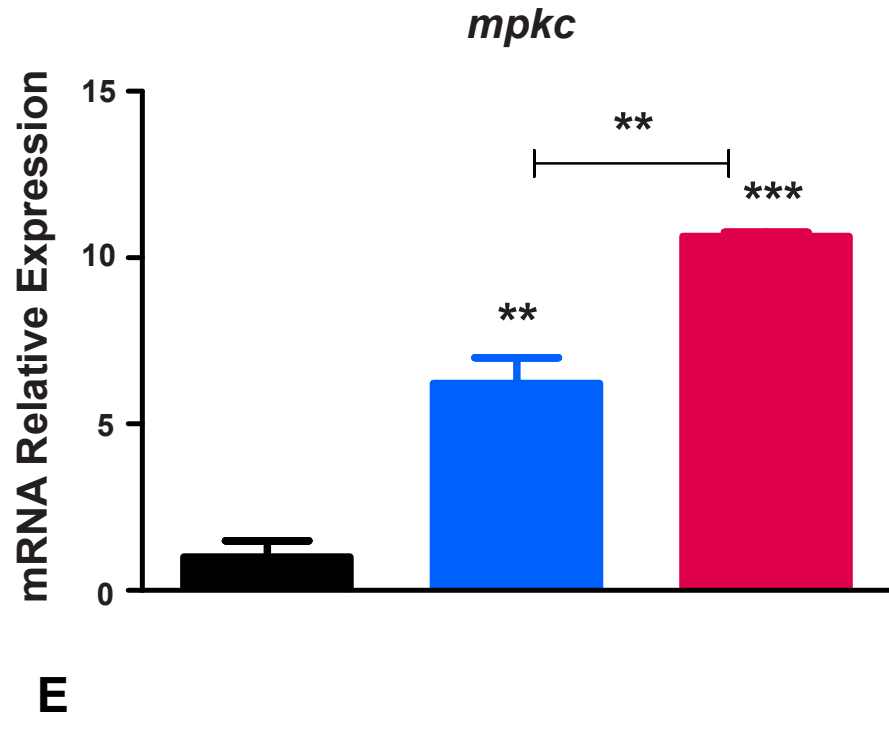

$\operatorname{nim} A$

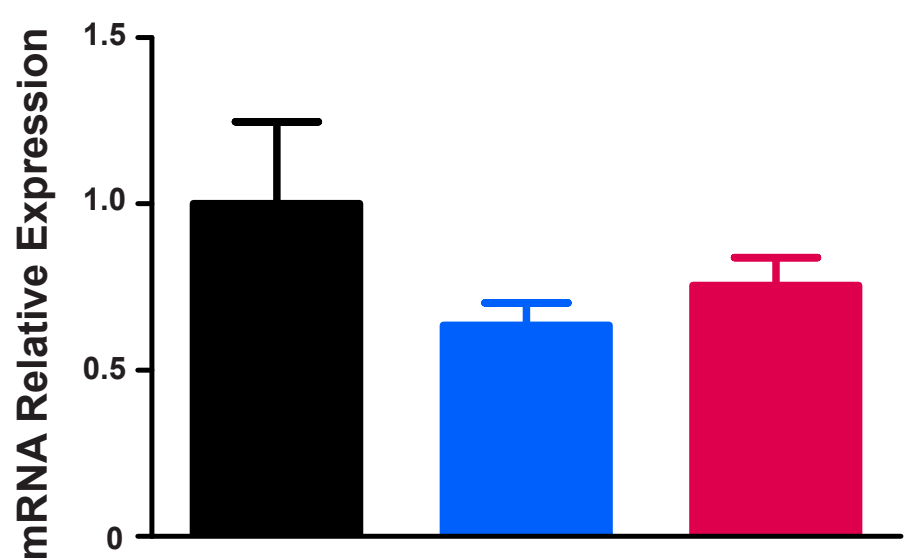


A

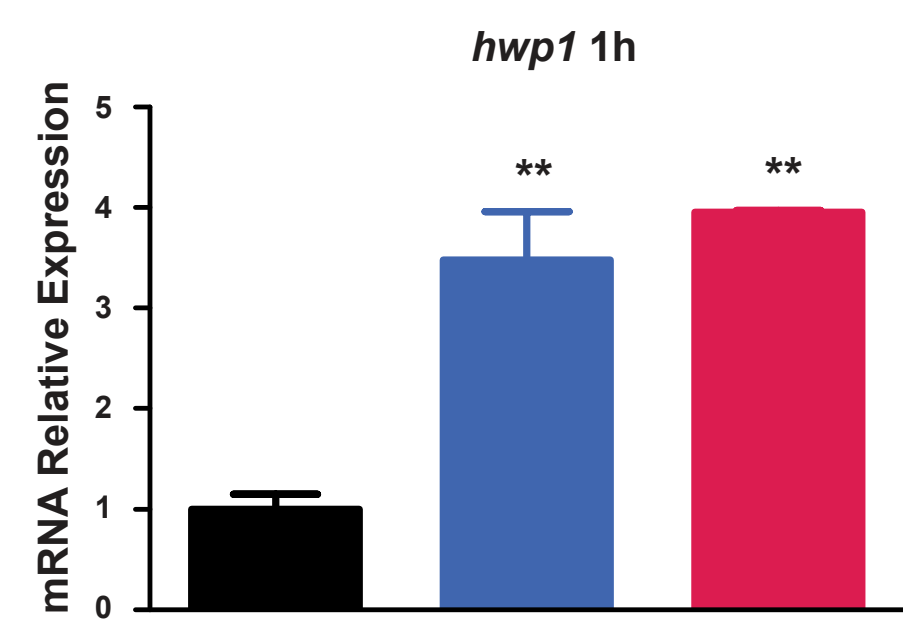

E

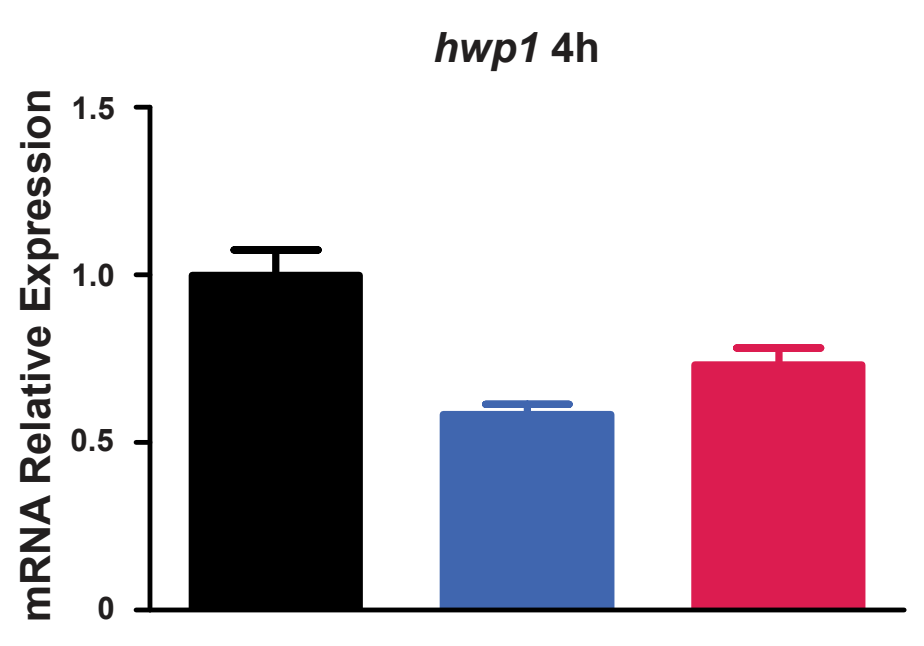

B

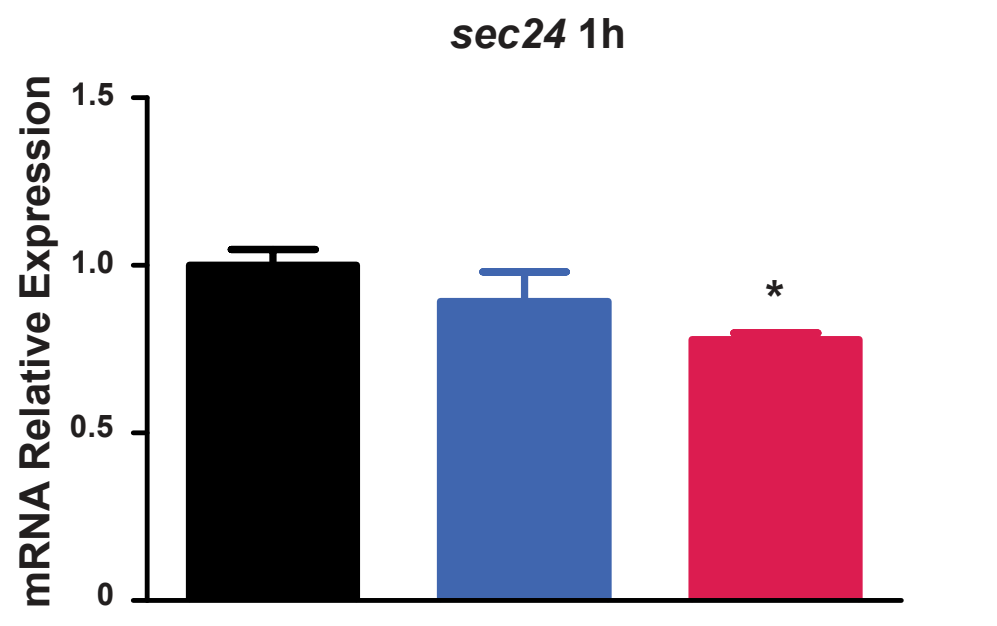

F

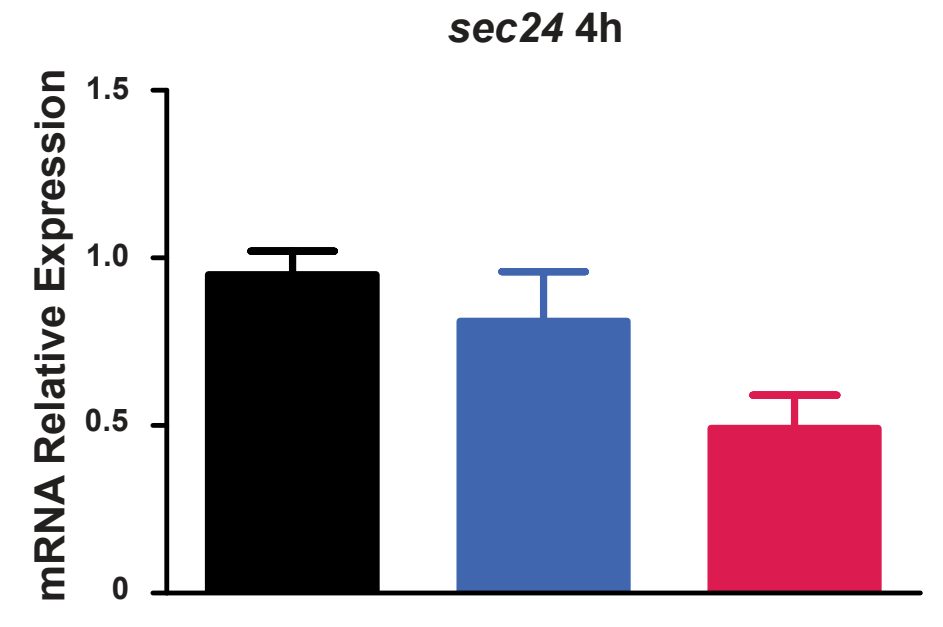

C
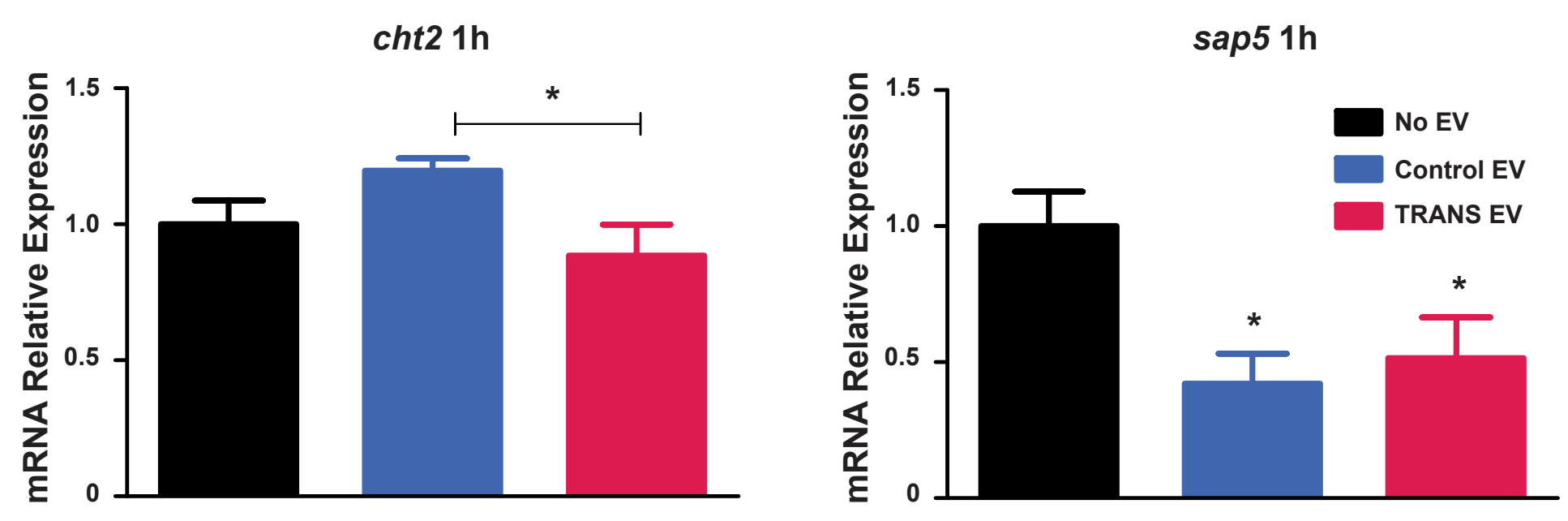

G

cht2 4h

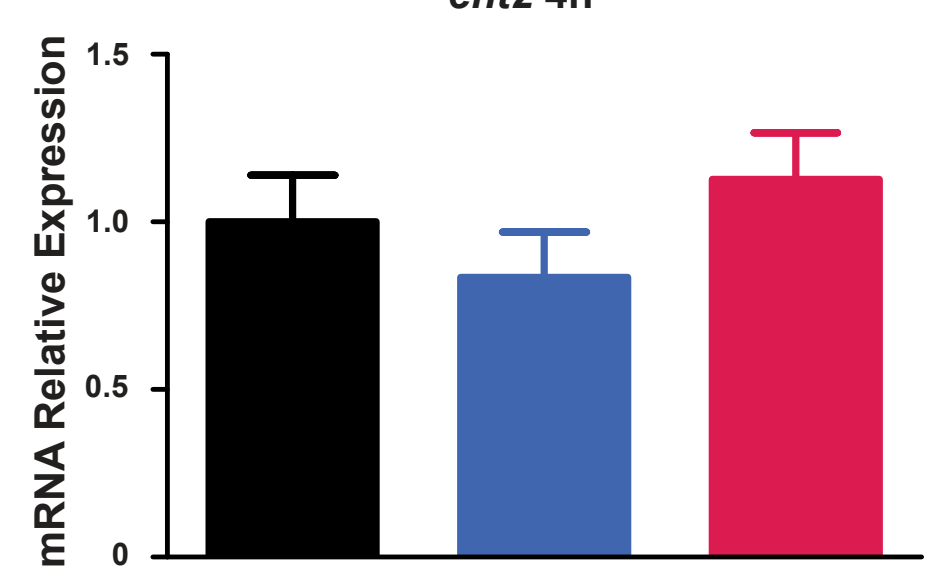

H

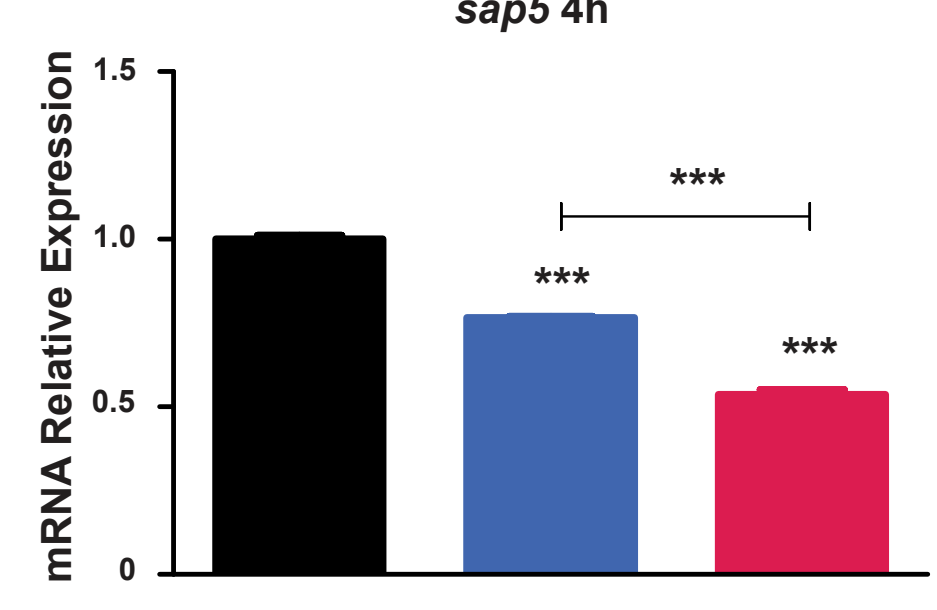

